\title{
ASPECTOS DA HIDRODINÂMICA DO AQUÍFERO ALUVIAL DO RIO JAGUARIBE, EM LIMOEIRO DO NORTE - CEARÁ
}

\author{
Hydrodynamic Aspects of The Alluvial Aquifer of Jaguaribe River in Limoeiro do Norte - Ceará
}

\author{
Diolande Ferreira Gomes ${ }^{1}$ e Horst Frischkorn ${ }^{1}$
}

\begin{abstract}
RESUMO: Os aquíferos aluviais são de grande importância para o desenvolvimento econômico, pois constituem uma importante fonte de água para diversos usos, e devem ser explotados em acordo com as potencialidades do recurso, para evitar tanto a degradação da qualidade como a redução do recurso hídrico. Neste trabalho são apresentados alguns aspectos hidrogeológicos do aluvião do rio Jaguaribe, que possibilitaram verificar que o rio Jaguaribe/Quixeré não recebe contribuição significativa dos aquíferos vizinhos em nenhuma época do ano. Na simulação do fluxo subterrâneo na ilha fluvial, ilha de Limoeiro, considerando o rio perenizado como limite do aquífero aluvial e 15\% das chuvas como recarga, observou-se que, em condições naturais, as cargas se estabilizam formando um divisor de águas na ilha de Limoeiro, situação esta que não foi observada na superfície piezométrica atual, o que evidencia que existem áreas com excessiva explotação da água subterrânea.
\end{abstract}

Palavras-chave: aquífero aluvial, rio Jaguaribe, superfície piezométrica, recarga

ABSTRACT: Alluvial aquifers are of great importance for the economic development. They represent an important source of water for various uses, which should be controlled and exploited in accordance with the potential of the resource to avoid both quality degradation and reduction of the water resource. In this paper, we present hydrogeologic aspects of the alluvium of Jaguaribe River that allowed verifying that Jaguaribe/Quixeré River does not receive any significant contribution from neighboring aquifers at any time of the year. In the computational simulation of groundwater flow on the fluvial island, the isle of Limoeiro do Norte, considering the perennial river as boundary of the alluvial aquifer and a recharge of $15 \%$ of rainfall, it was observed that, under natural conditions, the heads stabilize forming a water devide on the isle of Limoeiro do Norte. However, this situation was not observed in the actual piezometric surface, evidencing the existence of areas of groundwater over-exploitation.

Keywords: alluvial aquifers, Jaguaribe River, piezometric surface, recharge

\section{INTRODUÇÃO}

Com a perenização do rio Jaguaribe, tornase necessário conhecer melhor como ocorre a interação do rio Jaguaribe com os aquíferos sedimentares e fissural, para fornecer informações que possam auxiliar no gerenciamento dos recursos hídricos nesta parte do semi-árido. No interior do Estado, as áreas aluvionares são as principais fontes de água subterrânea de boa qualidade e elevada vazão, visto que nos terrenos cristalinos os poços captam águas salobras, que são usadas apenas para dessedentação de animais ou dessalinizadas para o abastecimento humano e onde devido à fertilidade desses solos, a principal atividade econômica desenvolvida é a agricultura irrigada. No aluvião do rio Jaguaribe, o uso excessivo da água proveniente de poços, sobretudo no período seco, pode acarretar uma perda de vazão do rio Jaguaribe, o qual é perenizado, e na depleção do aquífero. No intuito de contribuir nesse sentido, foi realizada esta pesquisa, que apresenta alguns aspectos da hidrodinâmica do aluvião do rio Jaguaribe. A área de estudo compreende um trecho onde o alargamento da planície aluvial é pronunciado.

Neste trecho, aproximadamente $5 \mathrm{~km}$ à jusante da localidade de Peixe Gordo, o rio Jaguaribe divide-se em dois braços, isolando uma faixa de terra com comprimento maior de $30 \mathrm{~km} \mathrm{e}$ largura média de $5,5 \mathrm{~km}$. Essa porção ilhada, de aproximadamente $170 \mathrm{~km}^{2}$, é conhecida como ilha de Limoeiro, na qual se situa a sede do município de Limoeiro do Norte. O braço oeste, neste trabalho, foi denominado rio Jaguaribe Oeste, e o braço leste, localmente, recebe o nome de rio Quixeré, e é nele que correm as águas do Jaguaribe. Nesse trecho do rio, estudos realizados por Gaspary et al. (1967), usando medidas das cargas nos poços, indicam interações entre o rio e os aquíferos vizinhos. As curvas piezométricas obtidas, no referido estudo, mostram que, durante a estação seca, o rio Quixeré drena as águas do aluvião e, durante a estação chuvosa, o rio alimenta os aluviões. Sales Neto (1997) usou dados hidroquímicos das águas do rio Jaguaribe e subterrâneas e dados isotópicos da água subterrânea para também estudar a interação rio-aquífero e, assim, tentar identificar 
a origem da perda de $5,7 \mathrm{~m}^{3} / \mathrm{s}$ na vazão medida pela FUNCEME (1994 apud SALES NETO, 1997), entre as seções de Peixe Gordo (município de Tabuleiro do Norte) e Estreito (município de Russas), ao longo do rio Jaguaribe. Atualmente, as demandas do rio Jaguaribe no trecho citado são para projetos de irrigação na Chapada do Apodi (cerca de $2,5 \mathrm{~m}^{3} / \mathrm{s}$ ), abastecimento e aquicultura. Neste trabalho pretende-se aprofundar as investigações sobre a inter-relação rio-aquífero, no baixo Jaguaribe.

\section{CARACTERIZAÇÃO DA ÁREA}

\section{Localização e Acesso}

A área de estudo está inserida na região do baixo Jaguaribe, abrangendo parte dos municípios de Limoeiro do Norte, Quixeré, Russas e Tabuleiro do Norte (Figura 1). O acesso principal, a partir de Fortaleza, é feito pela BR 116 até o km 190, daí toma-se a esquerda até a sede de Limoeiro do Norte, a $7 \mathrm{~km}$.

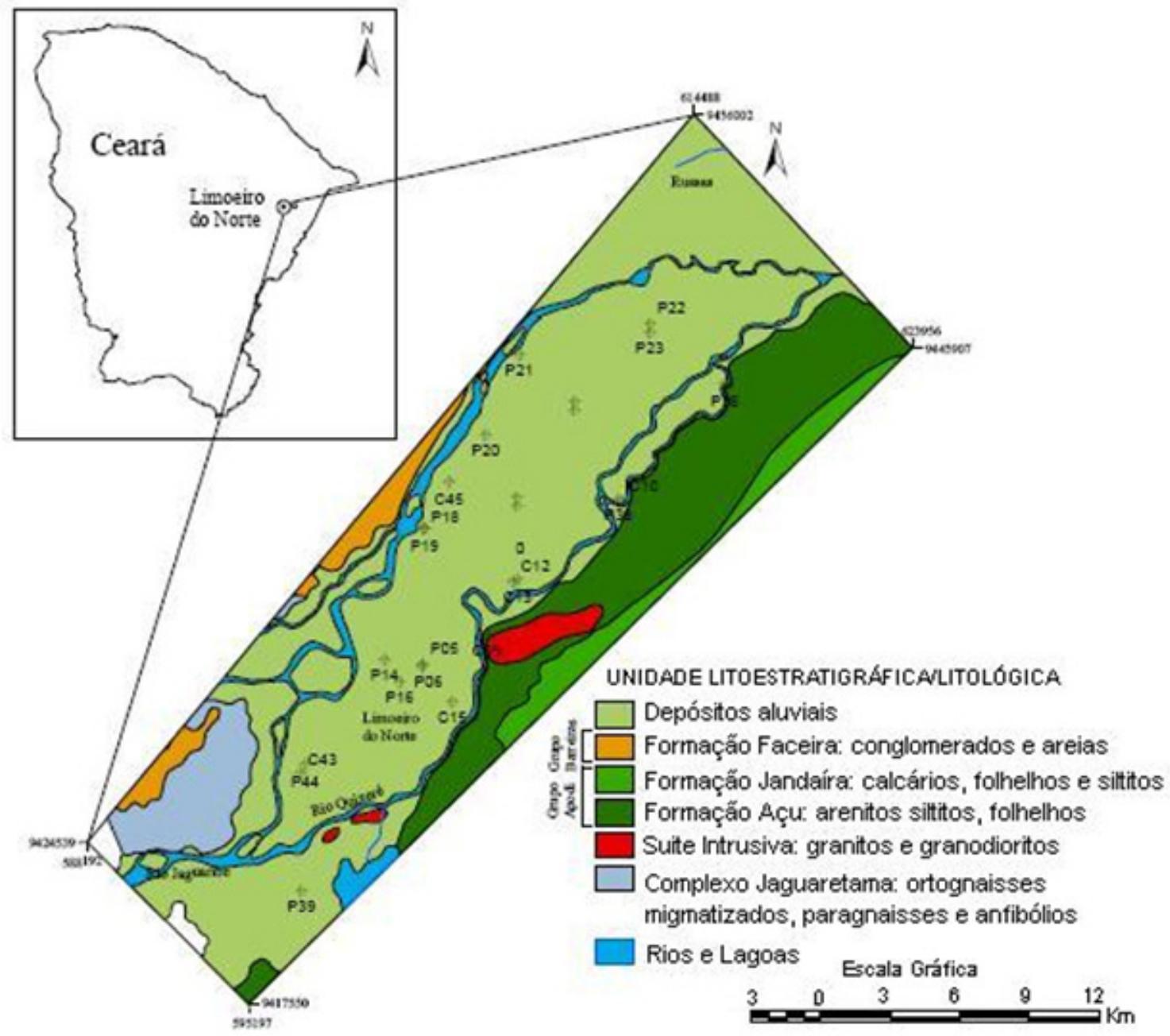

Figura 1: Mapa de localização da área e base geológica (CPRM, 2003)

Figure 1: Location map of the area and geological base (CPRM, 2003)

\section{Aspectos Econômicos}

$\mathrm{Na}$ bacia do rio Jaguaribe, a principal utilização do solo está ligada à atividade econômica agrícola. A renda advém da produção obtida com a safra, que passa a ser responsável pela manutenção da família durante todo o ano (IBGE, 1999). Outras atividades que geram renda para a população estão relacionadas à pecuária, exploração do calcário e de argila do leito dos rios e extrativismo.
De acordo com o levantamento feito pelos técnicos da Secretaria do Desenvolvimento Rural e Meio Ambiente do município de Limoeiro do Norte (SEDERMA, 2002), existem cerca de 1.160 produtores rurais em Limoeiro, entre os rios Jaguaribe Oeste e Quixeré. As áreas de plantação que ficam mais próximas do rio Jaguaribe Oeste são irrigadas com águas captadas de poços rasos construídos na calha do rio Jaguaribe Oeste, o qual é seco em algumas épocas do ano. Devido à facilidade de captar água subterrânea, geralmente 
com boa vazão e qualidade, cada produtor tem, no mínimo, um poço (com motor) e, às vezes, até quatro ou mais. As principais plantações na região de Limoeiro do Norte são: arroz, banana, coco, goiaba, graviola, limão e manga. Geralmente, a área para plantação do feijão é a mesma utilizada para o arroz; dependendo do preço do arroz, esse pode ser plantado no lugar do feijão.

Atualmente a principal cultura irrigada dos Vales do Jaguaribe e Banabuiu é o arroz, consumindo mais da metade da água com o método de inundação (ANA, 2002). Visando aumentar a eficiência do uso da água na agricultura, pelo combate ao desperdício e incentivo a sua conservação, o Governo do Estado do Ceará, em agosto de 2001, lançou o Plano Águas do Vale, que pretende estimular a utilização de sistemas e métodos de irrigação mais eficientes, e possibilitar trocar culturas que gastam muita água por outras que apresentem menor consumo, um maior valor de venda e ofereçam mais empregos.

\section{Aspectos Climáticos}

A área de estudo está localizada numa região onde a precipitação normal (IPLANCE, 1997) é de $750 \mathrm{~mm}$ nos municípios de Limoeiro do Norte e Tabuleiro do Norte e $850 \mathrm{~mm}$ nos municípios de Russas e Quixeré, resultando numa precipitação normal (dados de 1953 a 1983) para a região de 800 mm/ano. Para comparação: os municípios do estado do Ceará que se caracterizam pela escassez de chuva têm precipitação normal em torno de $500 \mathrm{~mm}$, e os municípios com maiores índices pluviométricos, estão situados em uma faixa hipsométrica com precipitação normal entre 1400 mm e 2000 mm (IPLANCE, 1997).

A análise dos dados pluviométricos da série temporal de 25 anos (1975 a 1999), do posto Limoeiro do Norte da FUNCEME, revelaram média mínima para o mês de outubro $(0,8 \mathrm{~mm})$ e máxima para o mês de março $(201 \mathrm{~mm})$, resultando numa elevada amplitude de 200,2 $\mathrm{mm}$. A distribuição temporal das chuvas na região, nesses 25 anos, mostra que o período chuvoso tende a iniciar em dezembro e terminar em julho. Sendo que, de dezembro até março, o volume precipitado aumenta e, a partir daí, diminui até parar de chover, iniciando o período seco, que vai de agosto até novembro (Figura 2). A média da precipitação total anual, da série de 25 anos, foi de $751 \mathrm{~mm}$, sendo que $697 \mathrm{~mm}$ (93\%) correspondem à precipitação acumulada nos meses de janeiro, fevereiro, março, abril e junho. De 1975 a 1999, a precipitação anual máxima foi $1624,4 \mathrm{~mm}$, ocorrida no ano de 1985 . E o ano de 1993 é considerado o mais seco, com $285 \mathrm{~mm}$ de precipitação pluviométrica.

Durante o monitoramento do nível estático, ou seja, de abril de 2000 a novembro de 2002, o ano mais chuvoso foi 2000, com $1.042 \mathrm{~mm}$, ultrapassando a precipitação média da região $(800$ $\mathrm{mm}$ ), enquanto 2001 foi um ano de escassez, com $411 \mathrm{~mm}$. No ano de 2002, a precipitação acumulada foi $841 \mathrm{~mm}$, semelhante à média da região, assim como a distribuição temporal (Figura 3).

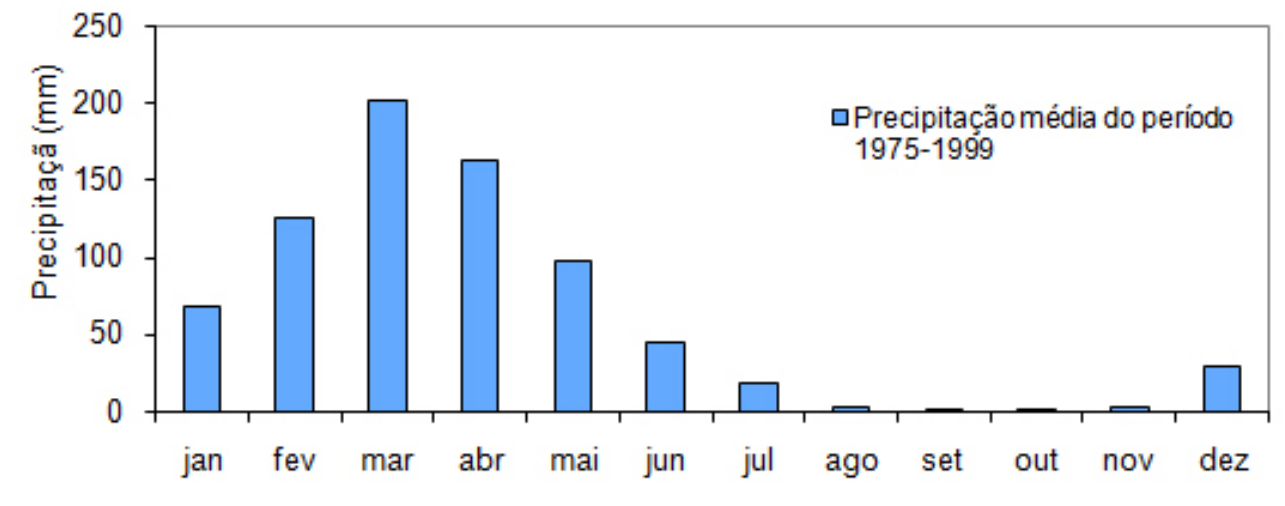

Tempo

Figura 2: Precipitação pluviométrica média do período de 1975 a 1999 no município de Limoeiro do Norte (posto Limoeiro do Norte/FUNCEME)

Figure 2: Average rainfall in the period 1975 to 1999 of Limoeiro do Norte (station Limoeiro do Norte) FUNCEME) 


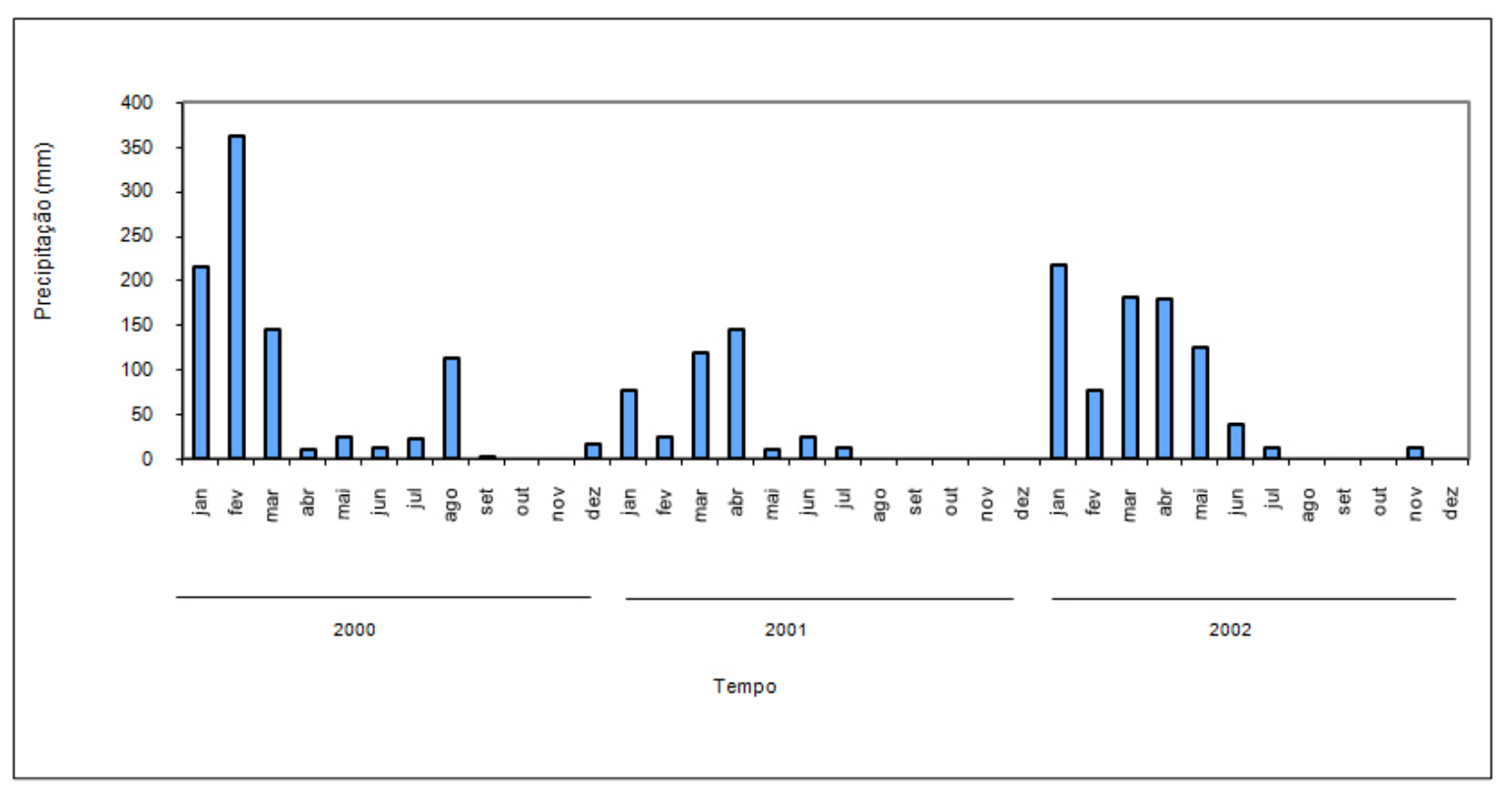

Figura 3: Precipitação pluviométrica, mensal e anual, no município de Limoeiro do Norte no período de estudo (posto Limoeiro do Norte/FUNCEME)

Figure 3: Rainfall, monthly and yearly in Limoeiro do Norte during the study period (Limoeiro do Norte) FUNCEME)

\section{Aspectos Geológicos e Hidrogeológicos}

Parte do Baixo Jaguaribe, onde está localizada a área, é formada por uma planície, com relevo bastante plano na zona dos aluviões. A margem direita do rio é limitada pelas rochas do Grupo Apodi. O Grupo Apodi é formado por uma sequência sedimentar de idade cretácea a terciária, que preenche a bacia Potiguar, sobreposta às rochas metamórficas e ígneas. As rochas do Grupo Apodi, que afloram na área de estudo, pertencem as Formações Açu e Jandaíra. Pela margem esquerda o rio é limitado pelas aluviões antigas da Formação Faceira do Grupo Barreiras (Figura1).

Os depósitos aluviais constituem a maior parte do Baixo Jaguaribe. Eles se estendem a partir de Tabuleiro do Norte, porção sul da área, formando uma planície de cerca de $10 \mathrm{~km}$ de largura por 100 km de comprimento, cobrindo as áreas que vão da BR-116 à encosta da Chapada do Apodi. Em geral, os depósitos aluvionares são representados por sedimentos areno-argilosos recentes, que ocorrem margeando as calhas dos rios e riachos que drenam a área. A recarga do aquífero está relacionada à pluviometria e rede hidrográfica.

As sondagens executadas no aluvião do baixo Jaguaribe, para avaliar as condições hidrogeológicas para perfuração de poços de abastecimento dos municípios de Quixeré e Tabuleiro do Norte (CAGECE, 1982), mostram as seguintes características para o aluvião à margem esquerda do rio Quixeré:

Em Quixeré: Existência de uma camada de areia muito heterogênea (de muito fina até conglomerática), em geral compreendida entre duas camadas argilosas: a superior siltosa amarronzada e a inferior compacta, de coloração marrom escura. A espessura do pacote aluvionar, em 12 sondagens, esteve entre 12,7 e 16,8 m, com nível estático entre 5,0 e 6,2 m, resultando em uma espessura saturada em torno de $9 \mathrm{~m}$. Na base, o aluvião está em contato com rochas da Formação Açu.

A cobertura aluvionar que reveste o leito do rio, na região de Quixeré, é constituída por areias argilosas, areias puras, argila e cascalhos. $\mathrm{Na}$ maioria das sondagens, a camada superficial, arenosa, compreende uma espessura entre 1,80 a 5,6 m, sobreposta a uma camada argilosa com espessura entre 1,2 e 2,2m.

Em Tabuleiro do Norte: O pacote aluvionar é constituído superficialmente por uma camada de material siltico-argiloso com espessura média de 2 a $3 \mathrm{~m}$, sobrepostos a areias grosseiras, que, por sua vez, repousam de forma discordante sobre os arenitos da formação Açu. A espessura saturada é em torno de $17 \mathrm{~m}$ e sua espessura exata depende exclusivamente do contato com os arenitos da Formação Açu. A espessura do pacote é estimada em 22 metros. 


\section{METODOLOGIA}

\section{Mapa da Superfície Piezométrica}

O mapa da superfície piezométrica foi construído a partir das medidas do nível estático (NE) dos poços e cota altimétrica (z) dos poços e rios, em relação ao nível do mar. No tratamento dos dados, o programa SURFER foi utilizado para traçar as isopotenciais, direção do fluxo e calcular volumes. O nível estático dos poços e cacimbas foi obtido, utilizando-se um medidor de nível, com sinal sonoro, marca Altronic. A carga hidráulica (h) é a soma de duas parcelas: a carga de elevação, z (altitude do ponto) e carga de pressão, $\mathrm{p} / \gamma$ (metros de coluna de água acima do ponto). No caso do aqǘf́ero livre, a carga na superfície livre (onde a pressão $\mathrm{p}$ é nula) corresponde ao próprio nível da água $(\mathrm{h}=\mathrm{z})$, ou seja, $\mathrm{h}=\mathrm{z}-\mathrm{NE}(\mathrm{CABRAL}, 1997)$

Coordenadas planialtimétricas

As coordenadas planialtimétricas foram determinadas utilizando receptores GPS, geodésico, de uma freqüência (L1), de precisão $1 \mathrm{~cm}+1 \mathrm{ppm}$. Foram utilizados RN's da Rede de Nivelamento de Precisão do IBGE. Adotou-se o método de Posicionamento Cinemático com taxa de rasteio de 5 segundos e tempo de ocupação nas estações de um minuto. O programa utilizado no processamento dos dados foi o Ashtech Solution 2.6.

\section{Modelo de Simulação}

A equação diferencial parcial que descreve o movimento tridimensional do fluxo subterrâneo, de densidade constante, sob condições de não estacionário, em um meio homogêneo e isotrópico, considerando o escoamento freático, é:

$$
\frac{\partial}{\partial x}\left(h \frac{\partial h}{\partial x}\right)+\frac{\partial}{\partial y}\left(h \frac{\partial h}{\partial y}\right)+\frac{\partial}{\partial z}\left(h \frac{\partial h}{\partial z}\right)=\frac{S_{y}}{k} \frac{\partial h}{\partial t}
$$

onde: $k$ - condutividade hidráulica ao longo dos eixos coordenados $\mathrm{x}, \mathrm{y}$ e z $(\mathrm{L} / \mathrm{T}) ; h$ - carga hidráulica ou nível potenciométrico (L); $S_{y}$ porosidade efetiva.

A solução analítica da equação do fluxo subterrâneo (Equação 1) não é simples, vários métodos numéricos podem ser aplicados na obtenção de uma solução aproximada. Entre eles, o mais usado atualmente é o Método das Diferenças Finitas, que consiste em substituir as derivadas na equação por aproximações numéricas de mesma ordem de aproximação. Neste método, a região é aproximada por uma malha formada por retângulos. Os espaçamentos podem ser constantes ou podem variar ao longo de cada eixo. Cada nó interno da malha representa uma porção limitada do aquífero a ser modelado, de modo que os parâmetros atribuídos a um nó são considerados constantes para a célula que ele representa. Em cada nó, cada derivada da expressão matemática do problema é aproximada por uma equação linear com referência aos nós adjacentes, formando um sistema de equações lineares, com uma equação para cada célula da malha, que é solucionada através de um modelo interativo. $\mathrm{O}$ programa utilizado para simulação das cargas hidráulicas e transferências de água rio-aquífero foi o Visual MODFLOW for Windows, versão 2.7.1. O modelo MODFLOW resolve a equação diferencial do fluxo subterrâneo (Equação 1), usando o método das diferenças finitas. A área a ser estudada é descrita como uma malha de células tridimensionais e o modelo estima as variações na carga, para cada célula (Figura 5).

Para calibração do modelo no estado transiente foram ajustadas as cargas piezométricas observadas, em poços distribuídos na ilha de Limoeiro, medidas entre novembro de 2000 e novembro de 2002, resultando em 12 campanhas, com as cargas calculadas pelo modelo. Desse

ajuste, foram obtidos os parâmetros $\left(k \mathrm{e} S_{y}\right)$ que caracterizam o aquífero e que foram utilizados nas simulações posteriores. Os melhores ajustes

foram obtidos com $k=2 \times 10^{-4} \mathrm{~m} \mathrm{~s}^{-1}$ e $S_{y}=0,1$, e resultaram em erros médios entre 0,03 e $0,7 \mathrm{~m}$ (Tabela 1). A Figura 4 ilustra o gráfico comparativo entre os valores observados e os calculados pelo modelo MODFLOW, com boa concordância, no período 7 .

Os valores iniciais das propriedades hidráulicas

( $k$ e $S_{y}$ ) foram obtidos dos testes de bombeamento executados na ilha de Limoeiro (GASPARY et al., 1967; CAGECE, 1982; CAGECE, 1999). Em termos de distribuição horizontal, a discretização do domínio foi feita em malha retangular, com espaçamento de $400 \times 700 \mathrm{~m}$. Os poços de observação/bombeamento ficaram centrados em células da rede definida por 50 linhas e 25 colunas (Figura 5) totalizando 1.250 nós. Através da ferramenta "grid", foram importadas, do SURFER, as superfícies topográficas e a da base do aquífero aluvial. As condições utilizadas no modelo foram: (i) carga constante, representando o rio perenizado que limita o aquífero. As pequenas flutuações da carga do rio, durante o tempo (0 724 d) também foram consideradas; e (ii) recarga, distribuída em toda a área e por período. A carga inicial é um parâmetro fixo, tomado como carga 
piezométrica da superfície freática, observada em campo, em 23/11/00 ( $t=0)$. O cálculo das vazões geradas pela carga constante e o volume acumulado no aquífero foi feito através do balanço de massa. Neste caso, a ferramenta "zone budget" foi aplicada para determinar as vazões na área com células ativas.

Tabela 1: Erros obtidos no melhor ajuste das cargas

Table 1: Errors obtained in the best fit of heads

\begin{tabular}{|c|c|c|}
\hline $\begin{array}{c}\text { Intervalo de tempo } \\
\text { (dias) }\end{array}$ & Período & Erro médio \\
\hline $0-29$ & 1 & $+0,10$ \\
\hline $29-71$ & 2 & $+0,29$ \\
\hline $71-114$ & 3 & $+0,26$ \\
\hline $114-151$ & 4 & $+0,52$ \\
\hline $151-205$ & 5 & $+0,30$ \\
\hline $205-244$ & 6 & $+0,05$ \\
\hline $244-288$ & 7 & $+0,20$ \\
\hline $288-350$ & 8 & $+0,40$ \\
\hline $350-429$ & 9 & $+0,05$ \\
\hline $429-511$ & 10 & $+0,027$ \\
\hline $511-594$ & 11 & $-0,062$ \\
\hline $594-724$ & 12 & $+0,70$ \\
\hline
\end{tabular}

+ Carga calculada maior que a carga observada

- Carga calculada menor que a carga observada

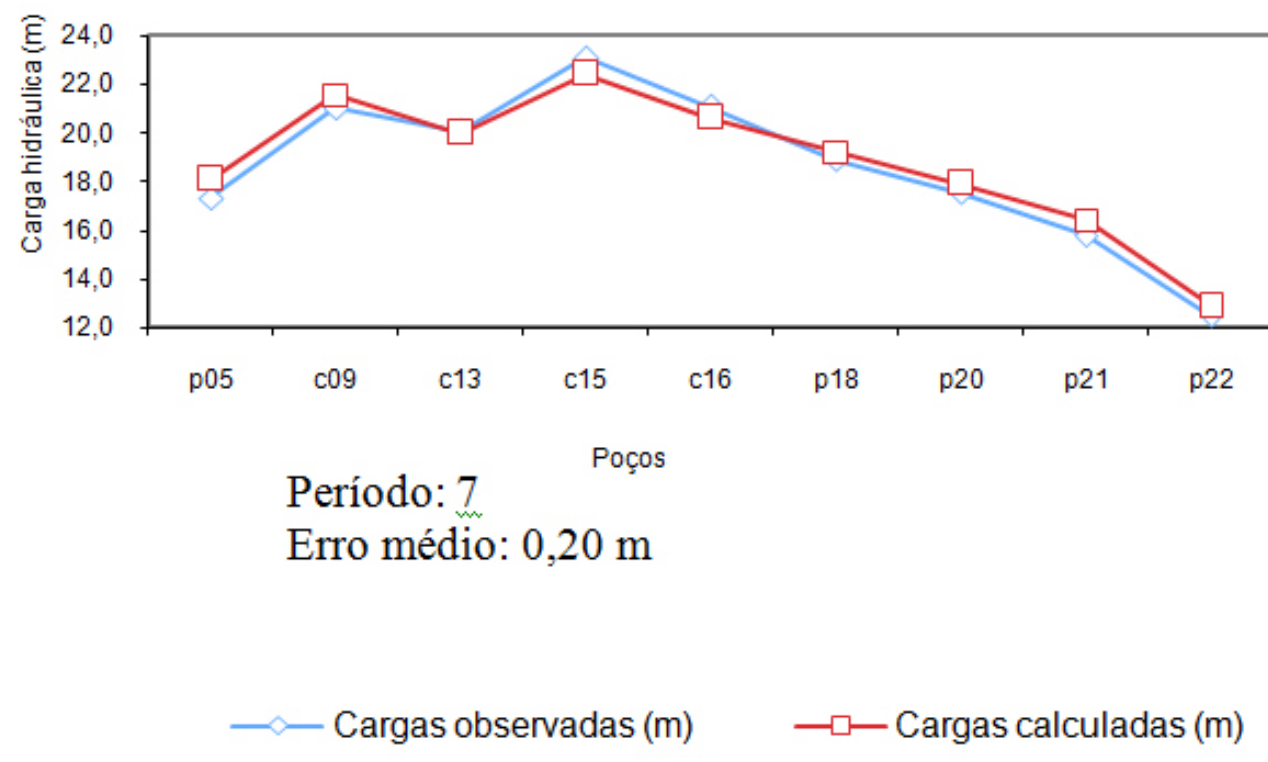

Figura 4: Comparação entre carga calculada pelo MODFLOW e carga observada (dados de campo)

Figure 4: Comparison between heads calculated by MODFLOW and heads observed (field data) 


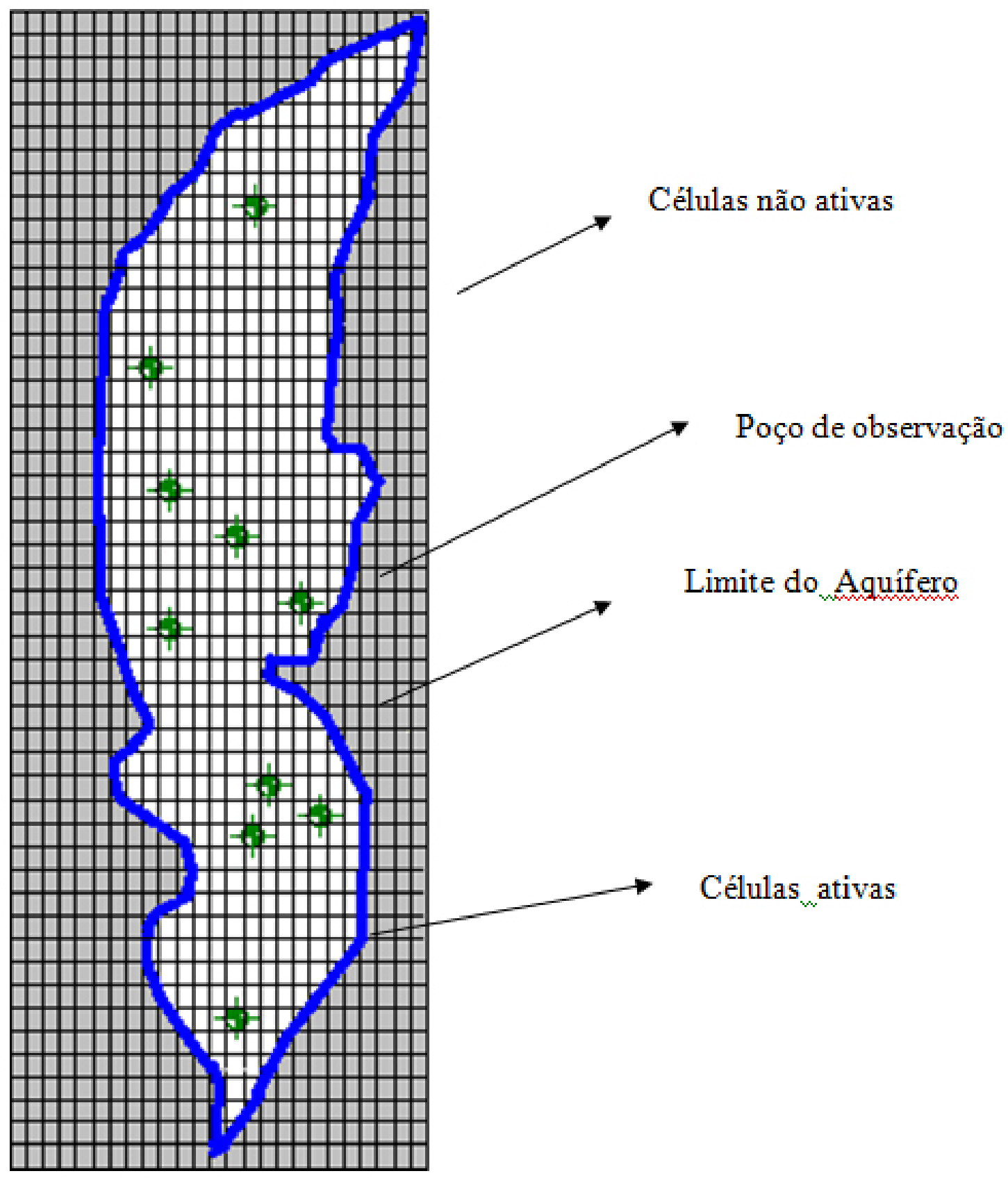

Figura 5: Mapa da área com malha para a calibração

Figure 5: Map of the area with grid for calibration

\section{RESULTADOS E DISCUSSÃO}

\section{Nível Estático (NE)}

A profundidade da água em relação ao solo, o nível estático, medida em 07 cacimbas e 14 poços, esteve entre 1,12 m (P36) e 10,08 m (P06), com média de $6,7 \mathrm{~m}$ e coeficiente de variação de 0,26 . As menores profundidades apareceram nos poços situados na margem leste do rio Quixeré mais próximos do rio ( $\mathrm{P} 36, \mathrm{C} 10$ e $\mathrm{C} 09)$, enquanto que a maior profundidade foi detectada na zona central da ilha de Limoeiro, nos poços P05 e P06, mais distantes do rio Quixeré.

\section{Variação Sazonal}

$\mathrm{O}$ maior valor da flutuação do NE foi de aproximadamente $2,0 \mathrm{~m}$, verificada nos poços $\mathrm{P} 05$ e P06, e o menor foi de $0,4 \mathrm{~m}$, no C10. A época em que se observou o NE mínimo variou entre abril, maio e julho, podendo chegar até setembro. Mas o mês do nível estático máximo foi geralmente sincronizado em novembro. 
$\mathrm{O}$ comportamento geral do NE evidencia que, entre abril e set/00, o NE é mínimo; a partir daí, ocorre a descarga do aquífero, o NE cresce alcançando o máximo em nov/00. Em dez/00, o NE começa a diminuir até atingir o mínimo do ano 2001, em abril-maio; após ocorrida então a alimentação natural do aquífero. Nos poços P16, P18 e P19, o nível estático mínimo ocorre cerca de um mês depois, em junho/01. Depois aumenta lentamente até nov/01, mês no qual é máximo em todos os poços. Em 2002, a alimentação do aquífero é evidenciada no período de fevereiro a julho. Nos poços da margem leste do rio Quixeré (C09, C10 e P36), o nível estático mínimo é registrado logo em fevereiro, enquanto nos poços entre os dois braços do rio, o mínimo é registrado apenas em julho.

Comparando as variações do nível estático com as precipitações, constata-se uma estreita relação, com uma pequena defasagem no tempo que corresponde ao tempo da infiltração.

As precipitações registradas em Limoeiro, Quixeré e Russas, para o ano de 2000, foram respectivamente $1129 \mathrm{~mm}, 769 \mathrm{~mm}$ e $1059 \mathrm{~mm}$ e, para o ano de 2001, foram $633 \mathrm{~mm}, 336 \mathrm{~mm}$ e $394 \mathrm{~mm}$. A média do conjunto é de $985 \mathrm{~mm}$ para o ano de 2000 e $454 \mathrm{~mm}$ somente para o ano de 2001. Considerando somente os aluviões da ilha de Limoeiro, com área de $170 \mathrm{~km}^{2}$, os volumes de água precipitados sobre a planície são respectivamente $16,7 \times 10^{7} \mathrm{~m}^{3}$ para 2000 e $7,7 \times 10^{5} \mathrm{~m}^{3}$ para 2001. A média destes dois valores é próxima do valor obtido a partir da série histórica (1974-2003) de pluviometria registrada no município de Limoeiro (estação Limoeiro), a qual fornece uma média de $751 \mathrm{~mm}(\mathrm{CV}=0,42)$, totalizando, portanto, 12,7 x $10^{7} \mathrm{~m}^{3} /$ ano de água precipitada sobre a ilha de Limoeiro.

\section{Superfície Piezométrica}

Os mapas potenciométricos permitem determinar zonas de alimentação e drenagem. O mapa foi realizado com poucos pontos de observação, mas distribuídos em toda ilha de Limoeiro. Para obter informações mais detalhadas do movimento da água, baseado apenas no mapa potenciométrico, necessitaria-se de um número maior de pontos de observação.

O mapa potenciométrico (Figura 6), elaborado através das medidas das cargas dos rios e dos poços, efetuadas num mesmo período (2123/11/02), apresenta um gradiente médio pequeno, de $0,5 \%$; porém, localmente, nas margens das zonas de depressão, aumenta passando para $2 \%$
(Tabelas 3 e 4). O fluxo subterrâneo tem direção independente da direção do rio e se move com velocidade de Darcy $(v=$ ki) média em torno de $9 \mathrm{~m} . \mathrm{ano}^{-1}$.

As curvas refletem apenas depressões na superfície piezométrica, chegando a formar curvas fechadas, indicando importantes retiradas locais. Essas perdas resultam de forte exploração, dificilmente de variações de permeabilidade ou forte evapotranspiração. Zonas muito permeáveis podem causar uma importante drenagem subterrânea, rebaixando a superfície piezométrica localmente. Apesar de serem poucas as informações sobre a permeabilidade do aquífero aluvial, os valores obtidos em diferentes setores da ilha são elevados $\left(\mathrm{k} \approx 10^{-4} \mathrm{~m} \mathrm{~s}^{-1}\right)$ e praticamente iguais, e na calibração do modelo MODFLOW, o aquífero se comportou como homogêneo e isotrópico. Portanto, as depressões têm, como causa fundamental, a explotação. Estão localizadas entre os dois rios, na ilha de Limoeiro, onde o aquífero drena as águas do rio (Tabela 2); apenas no setor norte, possivelmente, o aquífero passa a alimentar o rio (Figura 7).

A extração de água de um aquífero pode provocar um rebaixamento da superfície piezométrica, e, consequentemente, aumento dos gradientes hidráulicos. Tal rebaixamento induzirá, por conseguinte, maiores taxas de recarga do aquífero pelo rio. As medidas de $\delta^{18} \mathrm{O}$ de poços situados nessa área, estão próximas aos valores das chuvas locais em épocas de chuva $(-3,5)$ e tendem a aumentar em épocas de estiagem (GOMES, 2005), o que corrobora com a hipótese de uma recarga pelo rio, sobretudo, na época de estiagem. A sazonalidade isotópica verificada é um indicativo da recarga direta, cujas marcas isotópicas não foram "tamponadas" pelos processos de difusão e de mistura devido o tempo de residência muito curto.

Através dos poços localizados na margem direita do rio Quixeré (P39, C09 e C10), observa-se que nesta faixa as cargas são maiores que no rio (Tabela 3), indicando que, na ausência de bombeamento, esta zona não drena águas do rio. Mas esses poços, com exceção do $\mathrm{C} 10$, bombeiam cerca de $40 \mathrm{~m}^{3} /$ dia, além de outros, que, assim como os poços P36 e P39, são comunitários. Alguns destes poços chegam a secar durante o bombeamento; então são desligados para recuperação do nível d'água até o próximo dia. O poço $\mathrm{P} 36$ está situado na margem direita do Quixeré, relativamente distante do rio, mas a poucos metros $(11 \mathrm{~m})$ de um curso d'água intermitente. Nesse ponto, o aquífero está em 
equilíbrio com o rio (Tabela 3 ).

Pela distância entre esses poços (C09, P36, C10 e P39) e o rio, e devido ao bombeamento, esses têm maior conexão com o rio. As cargas mais elevadas podem ser consequência de permeabilidade menor, recarga natural, interação com outros aquíferos (Formações Jandaíra e Açú) ou alimentação indireta mediante escoamento sobre o relevo da escarpa da Chapada do Apodi. As medidas de $\delta^{18} \mathrm{O}$ dos poços P36 e C09 indicam águas evaporadas, $+3,58 \pm 0,7$ e $+2,07 \pm 0,3$, respectivamente, portanto, alimentação por águas superficiais, enquanto no P39, mais profundo (60 $\mathrm{m})$, o $\delta^{18} \mathrm{O}$ é negativo, mas com valor médio de $-1,25 \pm 0,10$, elevado em relação ao das chuvas, que também indica conexão com águas superficiais, embora muito menor, comparado com os poços P39 e C09, que captam águas diretamente do rio.

Os cursos de água superficial podem drenar ou alimentar os aquíferos freáticos. Em geral, alimentam os aquíferos freáticos em períodos de chuva e os drenam no período seco (CASTANY, 1975). Na ilha de Limoeiro, atualmente, esse comportamento não é observado. O mapa potenciométrico da Figura 6 foi realizado com medidas efetuadas no período mais seco do ano (novembro); nesse período, as linhas de fluxos convergiram para o centro da ilha, indicando fluxo de água das margens da ilha para o centro. O rio é perenizado, com somente pequenas variações de seu nível ao longo do ano; maiores elevações de nível são restritas a curtos períodos na época de chuva, quando acontecem escoamentos torrenciais. Mas isso é também a época de recarga direta do aluvião pelas chuvas, quando o nível d'água sobe rapidamente na ilha. Somente em determinados meses de chuva, por exemplo em abril/00, quando foi registrado uma subida do nível do rio $(3 \mathrm{~m}$ em relação a nov/02), pode se estabelecer um forte gradiente hidráulico do rio para aquífero.

Gaspary et al. (1967), através da análise da superfície piezométrica, com curvas demonstrativas da estação seca (janeiro/1964) e da estação chuvosa (maio-junho/1963), mencionam uma forte drenagem promovida pelo rio Quixeré, no período seco e atenuada no final da estação chuvosa; constatam uma segunda drenagem pelo Jaguaribe, na época seca, e alimentação das aluviões pelo Jaguaribe no final da estação chuvosa. Entre as duas drenagens, a mesma fonte menciona a possibilidade de alimentação em profundidade pelas águas subterrâneas de sequência arenítica (Formação Açu).

Comparando os dois cenários, um observado por Gaspary et al. (1967), quarenta anos atrás, e o outro, mostrando a situação atual, ficam claras as mudanças: o aluvião que cedia água para o rio passou a drená-lo. Estas mudanças estão associadas apenas com o aumento da atividade agrícola por irrigação, aumentando a demanda de água e a explotação intensa da água subterrânea.

Tabela 2: Gradiente hidráulico (i) entre o Rio Quixeré e poços nos dias 21-23/11/02

Table 2: Hydraulic gradient (i) from Quixeré river to wells on the days 21-23/11/02

\begin{tabular}{|c|c|c|c|c|c|c|}
\hline \multirow{2}{*}{$\begin{array}{c}\text { Número } \\
\text { do } \\
\text { Poço }\end{array}$} & \multicolumn{2}{|c|}{$\begin{array}{l}\text { Carga Hidráulica }(\mathrm{m}) \\
\text { em relação ao nível do mar }\end{array}$} & \multirow{2}{*}{$\begin{array}{l}\text { Distância } \\
\text { L(m) }\end{array}$} & \multirow{2}{*}{$\begin{array}{c}\text { i } \\
(\mathbf{H}-\mathbf{h}) / \mathbf{L}\end{array}$} & \multirow{2}{*}{$\begin{array}{c}\text { Condutividade } \\
\text { Hidráulica } \\
\left.\text { k(m.s } \mathbf{s}^{-1}\right)\end{array}$} & \multirow{2}{*}{$\begin{array}{l}\text { Velocidade do } \\
\text { fluxo } \\
\qquad \begin{array}{c}\text { v }=k . i \\
\left(m . a^{-1}\right)\end{array}\end{array}$} \\
\hline & Rio (H) & Poço (h) & & & & \\
\hline P44 & 25,5 & 24,0 & 2.143 & $+0,0007$ & \multirow{6}{*}{$2 \times 10^{-4}$} & 4 \\
\hline P05 & 24,0 & 17,0 & 2.858 & $+0,0024$ & & 15 \\
\hline P46 & 20,5 & 17,0 & 2.858 & $+0,0012$ & & 8 \\
\hline P22 & 15,0 & 12,0 & 2.000 & $+0,0015$ & & 9 \\
\hline $\mathrm{C} 15$ & 24,0 & 22,0 & 1.142 & $+0,0017$ & & 11 \\
\hline $\mathrm{C} 12$ & 20,0 & 19,0 & 715 & $+0,0014$ & & 9 \\
\hline
\end{tabular}


Tabela 3: Gradiente hidráulico (i) entre os poços situados na margem direita do Rio Quixeré e o Rio Quixeré, em 21-23/11/02

Table 3: Hydraulic gradient (i) from wells located on the right bank of the Quixeré river to Quixeré river, on $21-23 / 11 / 02$

\begin{tabular}{|c|c|c|c|c|c|c|}
\hline \multirow{2}{*}{$\begin{array}{c}\text { Número } \\
\text { do } \\
\text { Poço }\end{array}$} & \multicolumn{2}{|c|}{$\begin{array}{l}\text { Carga Hidráulica }(\mathrm{m}) \text { em } \\
\text { relação do nível do mar }\end{array}$} & \multirow{2}{*}{$\begin{array}{c}\text { Distância } \\
\text { L(m) }\end{array}$} & \multirow{2}{*}{$\begin{array}{c}\text { i } \\
(\mathrm{H}-\mathrm{h}) / \mathrm{L}\end{array}$} & \multirow{2}{*}{$\begin{array}{c}\text { Condutividade } \\
\text { Hidráulica } \\
\left.\text { K(m.s } \mathbf{s}^{-1}\right)\end{array}$} & \multirow{2}{*}{$\begin{array}{l}\text { Velocidade } \\
\text { do fluxo } \\
\qquad \begin{array}{l}\text { v }=k . i \\
\left(m . a^{-1}\right)\end{array}\end{array}$} \\
\hline & Rio (H) & Poço (h) & & & & \\
\hline $\mathrm{C} 09$ & 20 & 21 & 550 & $-0,002$ & \multirow{4}{*}{$2 \times 10^{-4}$} & 13 \\
\hline $\mathrm{C} 10$ & 19 & 20 & 1.430 & $-0,0007$ & & 4 \\
\hline P36 & 13 & 13 & 1.142 & 0 & & \\
\hline P39 & 24 & 26.5 & 3.000 & $-0,0005$ & & 3 \\
\hline
\end{tabular}

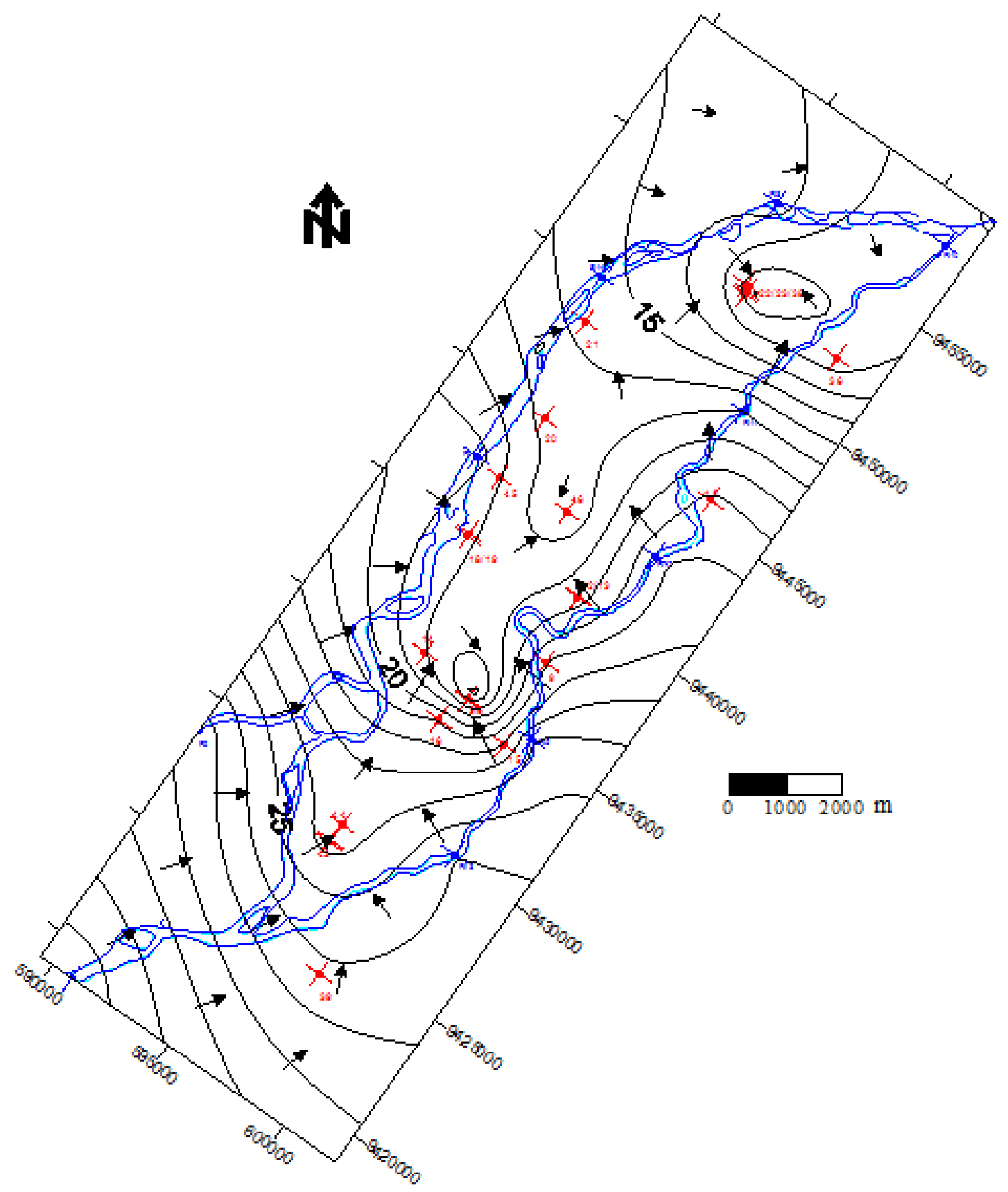

Figura 6: Mapa potenciométrico do aquifero aluvial, em 21-23/11/02

Figure 6: Potentiometric map of the alluvial aquifer on 21-23/11/02 


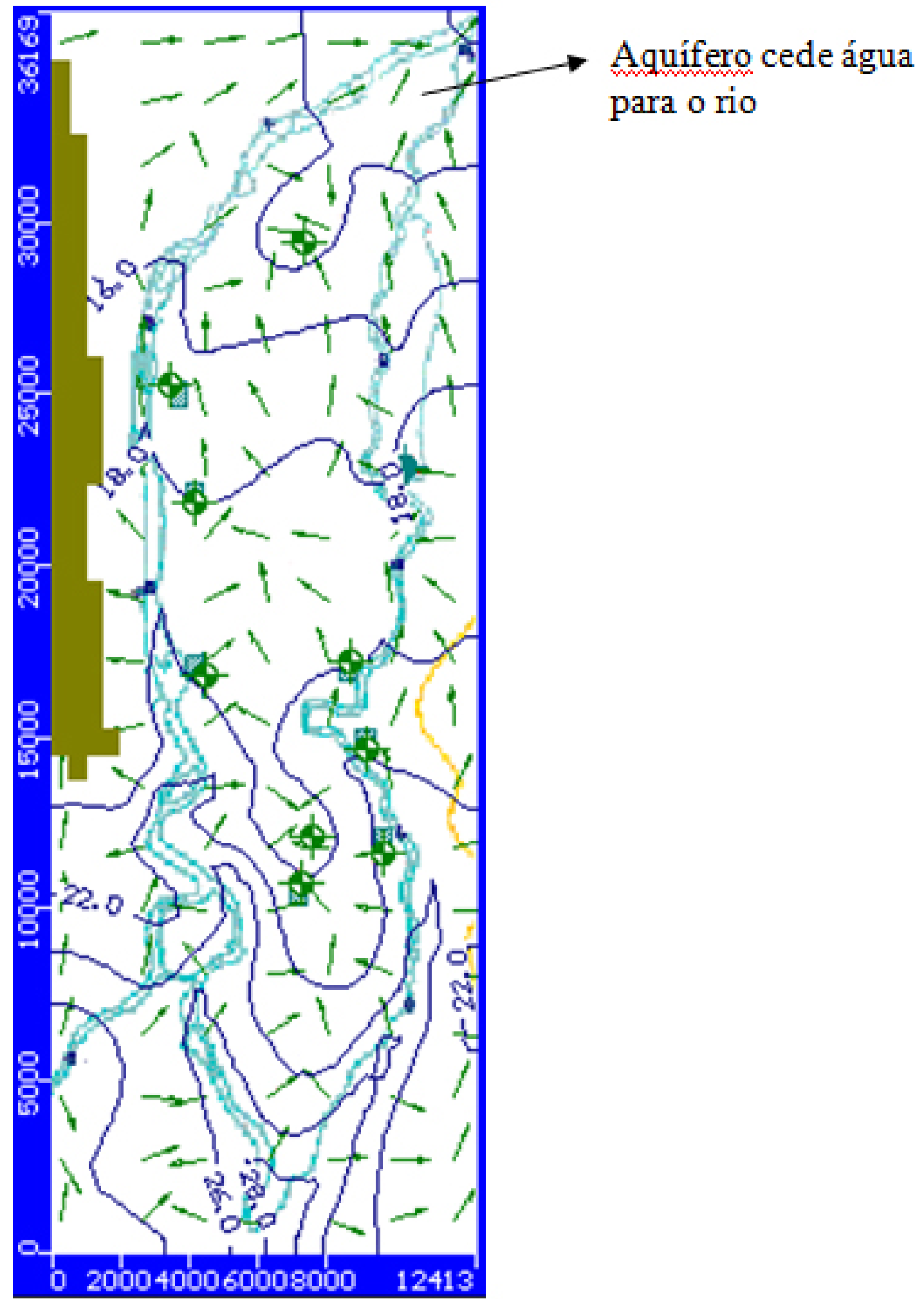

Figura 7: Equipotenciais e direção do fluxo subterrâneo na ilha de Limoeiro do Norte, geradas na calibração do MODFLOW (período 7; 07/fev/01)

Figure 7: Equipotentials and groundwater flow direction on the isle of Limoeiro, generated in the calibration of MODFLOW (period 7; 07/fev/01) 


\section{Avaliação das reservas}

A avaliação quantitativa, bem como a qualitativa, das reservas de água do aquífero aluvial se revestem de extrema importância por nortear seu aproveitamento. $\mathrm{O}$ aspecto quantitativo das águas armazenadas no aquífero aluvial é analisado a seguir, determinando-se as reservas permanentes e reguladoras.

Os dados dimensionais que determinam as reservas de águas subterrâneas podem ser fixos, por substrato e camada confinante de aquíferos confinados, ou variáveis, definidos pelo substrato e a superfície piezométrica dos aquíferos livres (CASTANY, 1975).Portanto, ovolume armazenado na camada aquífera do aluvião da ilha de Limoeiro é delimitado na base pelo substrato impermeável, contorno constante, e no topo pela superfície piezométrica, afetada por flutuações periódicas. Assim, o cálculo das reservas do aquífero livre se baseia essencialmente no estudo das flutuações médias da superfície piezométrica durante o ciclo hidrológico. O período aqui considerado para avaliação das reservas corresponde a dois anos e sete meses. Não foi usada a flutuação de apenas um ano, ou a média dos anos, porque, por exemplo, no primeiro ano foram poucos os poços monitorados, que estavam localizados somente numa parte da Ilha. No segundo ano, já havia um número maior de poços distribuídos em toda a área, no entanto, alguns foram fechados, impossibilitando a medição do nível estático; no terceiro ano, foram acrescentados mais poços, mas foram poucos os meses de observação do nível estático; no entanto, as medições abrangeram o final do período chuvoso e final do período seco. Também foram usados dados históricos de nível para obter níveis potenciométricos mínimos para avaliar a reserva permanente.

É difícil calcular com suficiente precisão as reservas subterrâneas partindo dos mapas potenciométricos e da superfície da base do aluvião, devido a escassez de pontos de observação e por causa das zona de superexploração em grande área. Cabe aos órgãos responsáveis pelo gerenciamento dos recursos hídricos dar continuidade ao monitoramento dos poços e instalar piezômetros no aluvião, para, assim, obter uma base de dados confiável para o planejamento.

\section{Reservas reguladoras $\left(\mathbf{R}_{\mathrm{r}}\right)$}

No transcurso de um ciclo hidrológico determinado, a superfície piezométrica oscila entre um nível mínimo e um nível máximo. Estas posições extremas limitam uma camada do aquífero cujo volume de água correspondente representa as reservas reguladoras, os recursos explotáveis, ou seja, o volume máximo que o aquífero poderá fornecer sem depleção.

Adotando $\Delta \mathrm{V}$ para o volume entre as superfícies piezométricas, mínima e máxima (Figuras 8 e 9) do aquífero aluvial, calculado pelo programa SURFER através da regra trapezoidal, e uma porosidade eficaz média de $10 \%$, utilizada nas simulações com o uso do MODFLOW, obtevese uma reserva reguladora de $18 \times 10^{6} \mathrm{~m}^{3} / \mathrm{a}$. Este volume $\left(\mathrm{R}_{\mathrm{r}}\right)$ corresponde a uma variação média

nas cargas $\left(\Delta h=\frac{R_{r}}{A^{*} S y}\right)$ de aproximadamente $1,1 \mathrm{~m}$, o qual representa cerca de $15 \%$ $\left(\frac{\Delta h * S y}{P} * 100\right)$ da precipitação média $(0,76 \mathrm{~m})$ do período observado.

No equilíbrio, sem explotação de águas subterrâneas, a fração da precipitação que alimenta as águas subterrâneas (infiltração eficaz) é igual à variação das cargas $(\Delta \mathrm{h}) \mathrm{Na}$ ilha de Limoeiro há explotação para irrigação e abastecimento, podendo consequentemente acentuar o rebaixamento natural da superfície piezométrica, gerando um $\Delta \mathrm{h}$ maior se a retirada for, por exemplo, apenas no período mais seco do ano. Mas, como as retiradas ocorrem praticamente durante todo o ano, devido a irrigação de culturas perenes e duas safras, a variação causada no nível potenciométrico $(\Delta \mathrm{h})$ é igual a variação do sistema no equilíbrio. Desta forma, pode-se considerar que cerca de $15 \%$ da precipitação sobre a ilha recarrega o aluvião.

Usando as superfícies piezométricas, mínima e máxima, correspondentes às medições de nível estático do período de 02/02-11/02 para calcular a reserva, também foi encontrado um volume de água livre de $18 \times 10^{6} \mathrm{~m}^{3}$. 


\section{Reservas permanentes $\left(\mathbf{R}_{\mathrm{p}}\right)$}

As reservas permanentes representam o volume de água armazenada na camada aquífera limitada na base pelo substrato impermeável e no topo pela superfície piezométrica mínima, ou preferencialmente, uma superfície piezométrica mínima média de longo prazo. Nesse último caso, trata-se das reservas permanentes médias.

Atualmente, a superfície piezométrica mínima está abaixo do nível da condição de equilíbrio rioaquifero devido às retiradas por bombeamento de uma parte da reserva permanente, limitada no topo pela superfície piezométrica no equilíbrio. Há 18 anos, quando foi construído o poço P05, seu nível estático era $4 \mathrm{~m}$. A carga correspondente era $23 \mathrm{~m}$; atualmente, a carga máxima deste poço é $19 \mathrm{~m}$. Com o uso do MODFLOW, usando como sendo a carga inicial para a simulação a superfície piezométrica máxima atual (Figura 8) e o aquífero limitado pelas cargas constantes (rio perenizado), pôde-se observar as mudanças das cargas no tempo (Figura 10), até o poço 05 chegar à carga de $23 \mathrm{~m}$, reconstituindo-se a superfície piezométrica máxima no intervalo 1985-2002. O volume entre essa superfície piezométrica e a base da aluvião, calculado pelo programa Surfer, é de $18 \times 10^{8} \mathrm{~m}^{3}$. Adotando a porosidade eficaz média de $10 \%$, obteve-se a reserva permanente de $18 \times 10^{7} \mathrm{~m}^{3}$. A espessura saturada media para este volume de reserva é aproximadamente $11 \mathrm{~m}$.

A reserva acumulada nos aluviões da ilha de Limoeiro foi calculada primeiramente por Gaspary et al. (1967) na zona de maior espessura saturada, onde foi verificada maior susceptibilidade de uma valorização da terra. $\mathrm{O}$ volume encontrado foi $15 \times 10^{7} \mathrm{~m}^{3}$. Nesse cálculo foi adotada uma porosidade eficaz de $10 \%$, espessura saturada média de $12 \mathrm{~m}$, e área de $120 \mathrm{~km}^{2}$. A diferença entre a reserva calculada por Gaspary (op cit) e neste trabalho, de $18 \%$ (em relação a média), torna-se menor, se for considerada, no trabalho de Gaspary (op cit.) toda a área da ilha.

\section{Explotacão do Aquífero}

As retiradas totais do aluvião nos últimos dezoito anos são a soma de três parcelas: recarga, volume de água livre entre a superfície piezométrica de 1985 e a superfície máxima atual e alimentação do aluvião pelo rio.
$\mathrm{O}$ volume contido entre a superfície piezométrica de 1985 e a atual, calculado pelo SURFER, multiplicado pela porosidade eficaz, é $30 \times 10^{6} \mathrm{~m}^{3}$. Este déficit acumulado, causado pelas retiradas de água subterrânea para irrigação, em aproximadamente 18 anos, representa cerca de $16 \%$ da reserva permanente. O déficit anual é $1,7 \times 10^{6} \mathrm{~m}^{3}$, causando um rebaixamento médio de aproximadamente $10 \mathrm{~cm}$ por ano.

Na simulação com MODFLOW para encontrar o déficit acumulado em 18 anos, para comparação com o volume encontrado pelo SURFER, foi usada a ferramenta "ZBUD" do balanço de massa. $\mathrm{O}$ volume de água obtido corresponde apenas à alimentação do aluvião pela carga constante (rio) até o sistema (rio-aquífero) entrar em equilíbrio; portanto, não é introduzida recarga pela chuva. Nesta simulação, a condição de contorno, ou seja, o limite do aquífero, é a carga constante, que é o rio perenizado. A carga inicial $\left(\mathrm{h}_{\mathrm{o}}\right)$ é a superfície piezométrica máxima atual. A variação do volume versus tempo (Figura 11) mostra que o volume se estabiliza em aproximadamente $22 \times 10^{6} \mathrm{~m}^{3}$. A diferença entre os dois métodos de calcular o volume é de 30\% (em relação ao valor médio).

$\mathrm{Na}$ simulação da alimentação da aluvião pelo rio, o volume também foi obtido da mesma forma anterior. No entanto, procurou-se executaro modelo no menor tempo possível (1 segundo), de forma que o gradiente hidráulico entre a carga constante (rio) e a superfície piezométrica do aquífero $\left(\mathrm{h}_{\mathrm{o}}\right)$, fosse mantido. A alimentação do aluvião pelo rio, ou seja, a infiltração do rio, calculada pelo MODFLOW, no tempo aproximadamente zero, foi $35 \times 10^{3} \mathrm{~m}^{3} \mathrm{~d}^{-1}\left(12,7 \times 10^{3} \mathrm{~m}^{3} \mathrm{a}^{-1}\right)$ (Figura 12), que representa $7 \%$ da vazão média do rio Jaguaribe (em Peixe Gordo, ponto R03).

As retiradas de água superficial e subterrânea para irrigação, na ilha de Limoeiro, somam cerca $12 \times 10^{7} \mathrm{~m}^{3} / \mathrm{a}$ (GOMES, 2005). Um grande percentual de água subterrânea usado na irrigação, não retorna ao aquífero, causando depressões na superfície piezométrica, mesmo no setor em que ocorre importante alimentação pela precipitação local.

As retiradas anuais de água subterrânea do aluvião somam aproximadamente $3,2 \times 10^{7} \mathrm{~m}^{3} \mathrm{a}^{-1}$, portanto $8,8 \times 10^{7} \mathrm{~m}^{3} \mathrm{a}^{-1}$, usados na irrigação, são retirados diretamente do rio. 


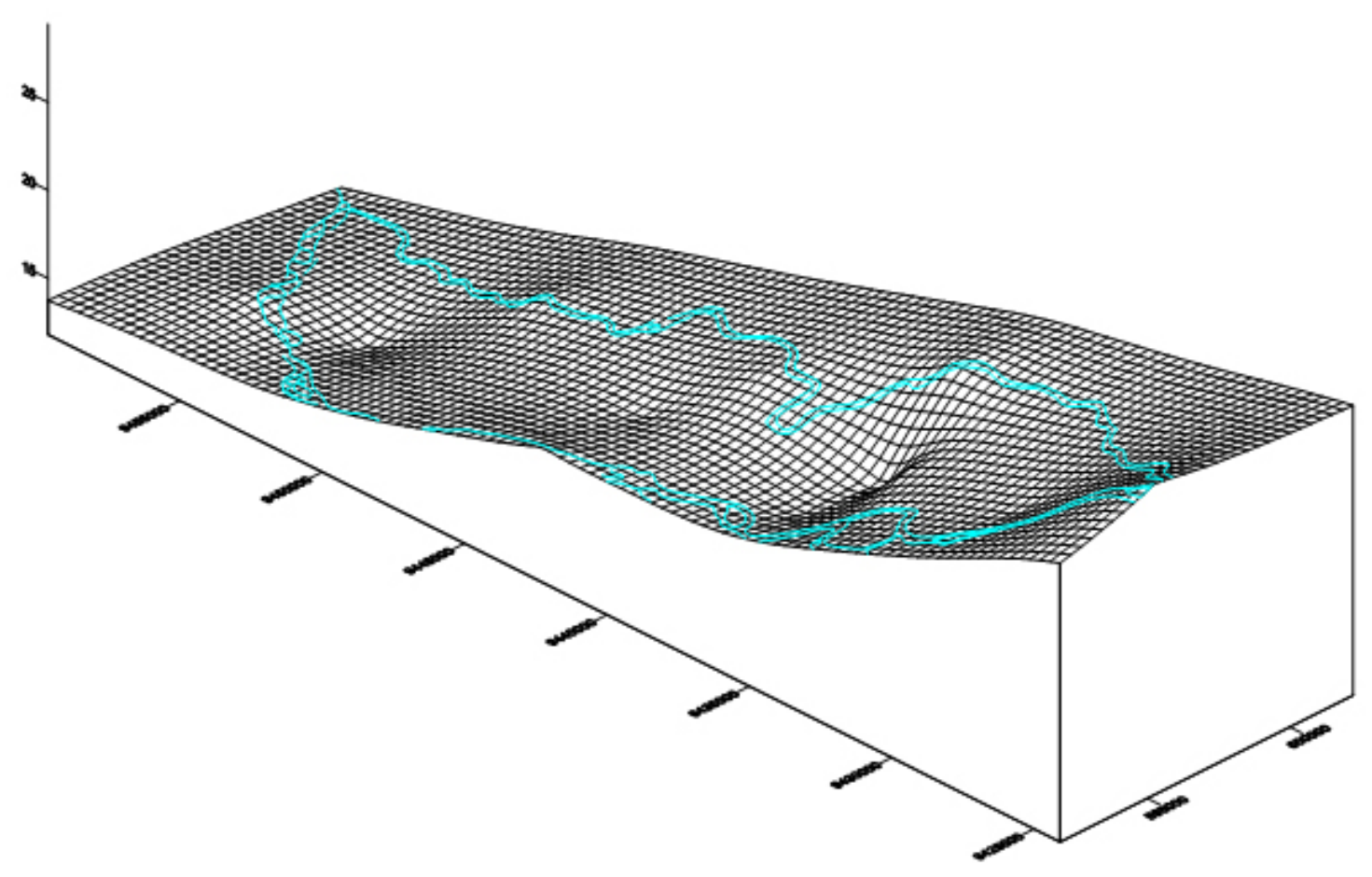

Figura 8: Superfície piezométrica máxima, no periodo 04/00-11/02

Figure 8: Maximum piezometric surface in the period 04/00-11/02

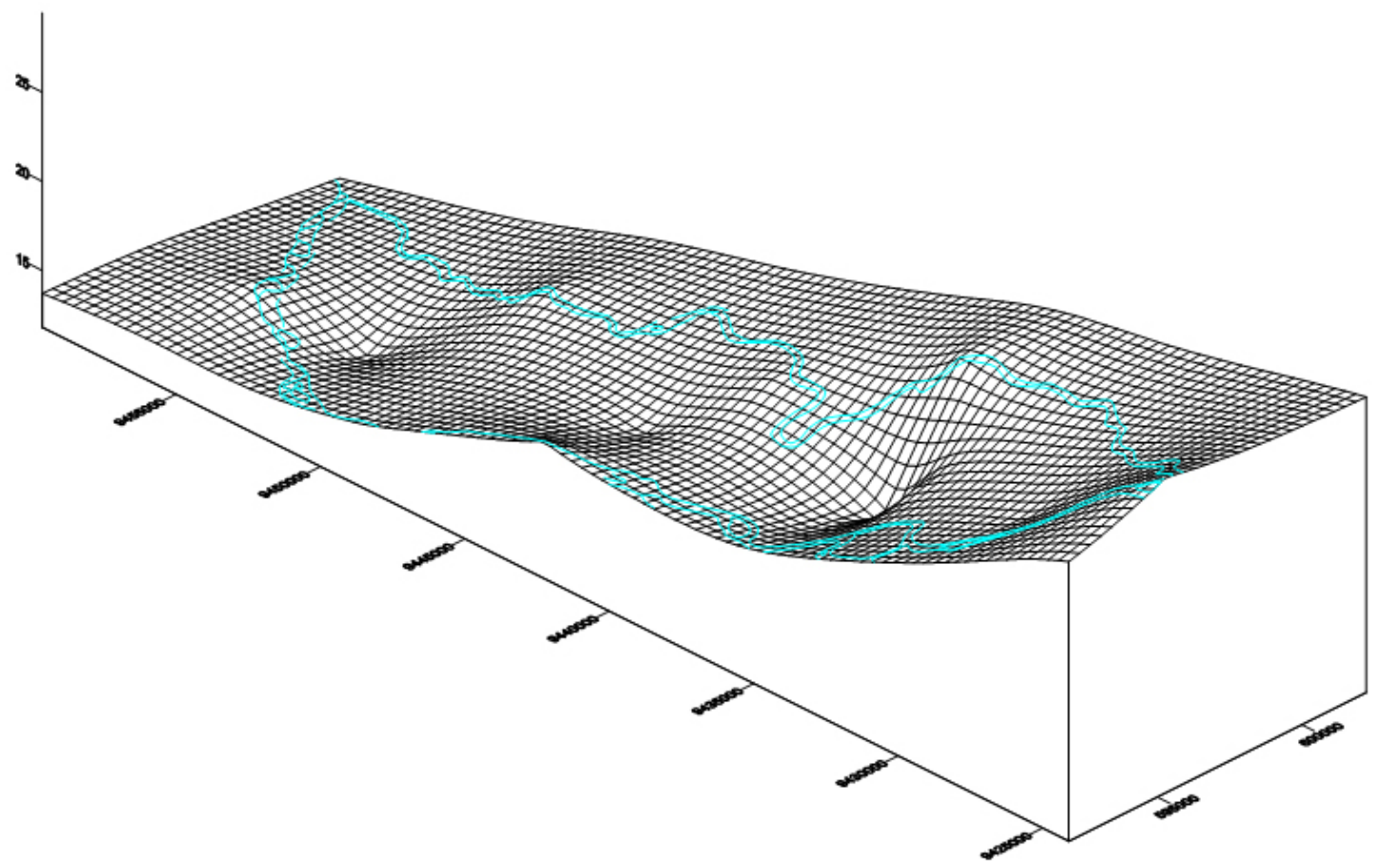

Figura 9: Superficie piezométrica mínima, no periodo 04/00-11/02

Figure 9: Minimum piezometric surface in the period 04/00-11/02 


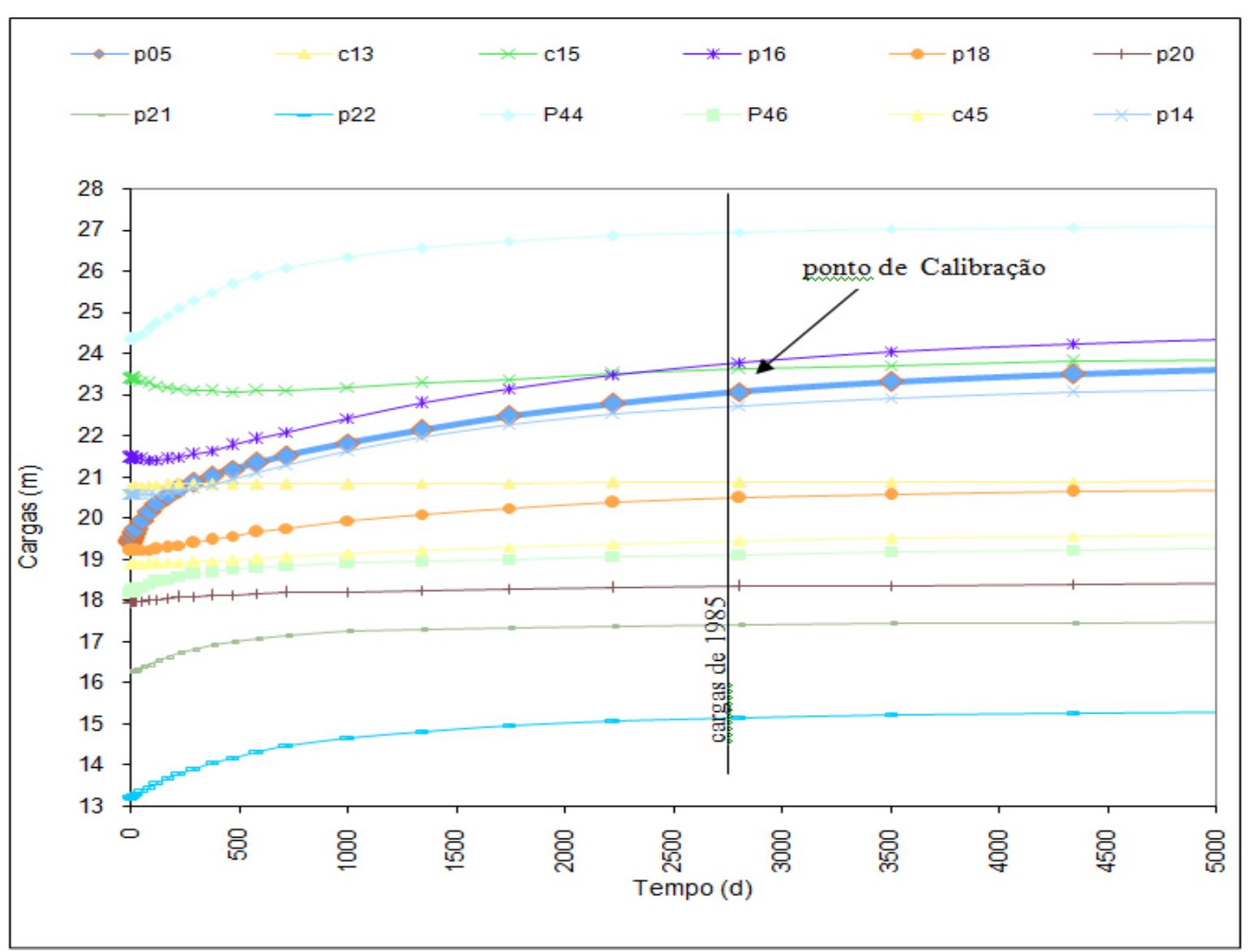

Figura 10: Cargas calculadas pelo MODFLOW para obtenção da superfície piezométrica de 1985

Figure 10: Heads calculated by MODFLOW to obtain the piezometric surface for 1985

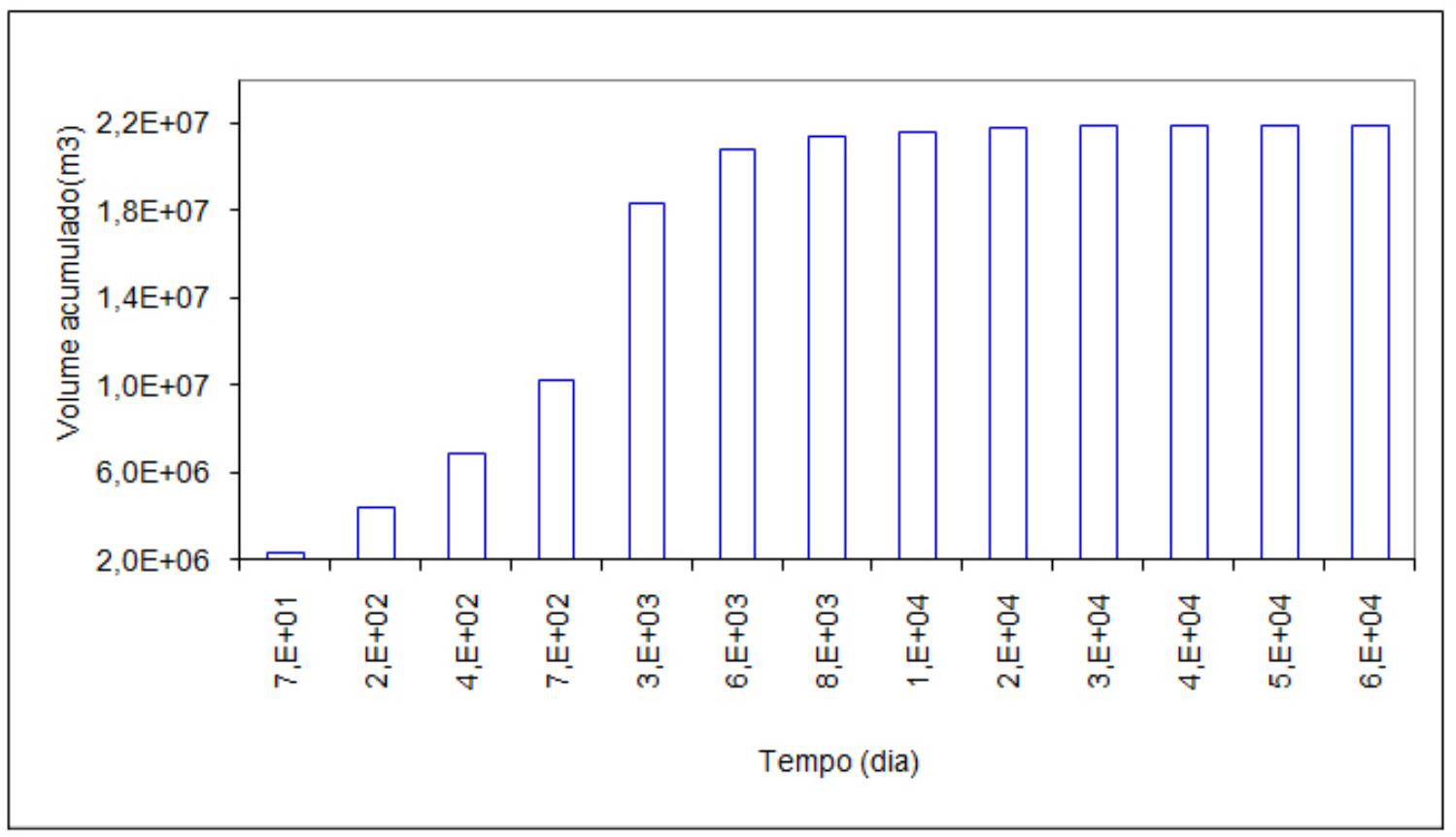

Figura 11: Volume acumulado entre a superficie piezométrica máxima atual e a superficie de 1985, calculado pelo MODFLOW. O volume no equilibrio (rio-aquifero) representa o déficit acumulado (retiradas) num periodo de 18 anos

Figure 11: Volume accumulated between the actual maximum piezometric surface and the surface of 1985, calculated by MODFLOW. The volume at equilibrium (river-aquifer) represents the accumulated deficit (withdrawals) over a period of 18 years 


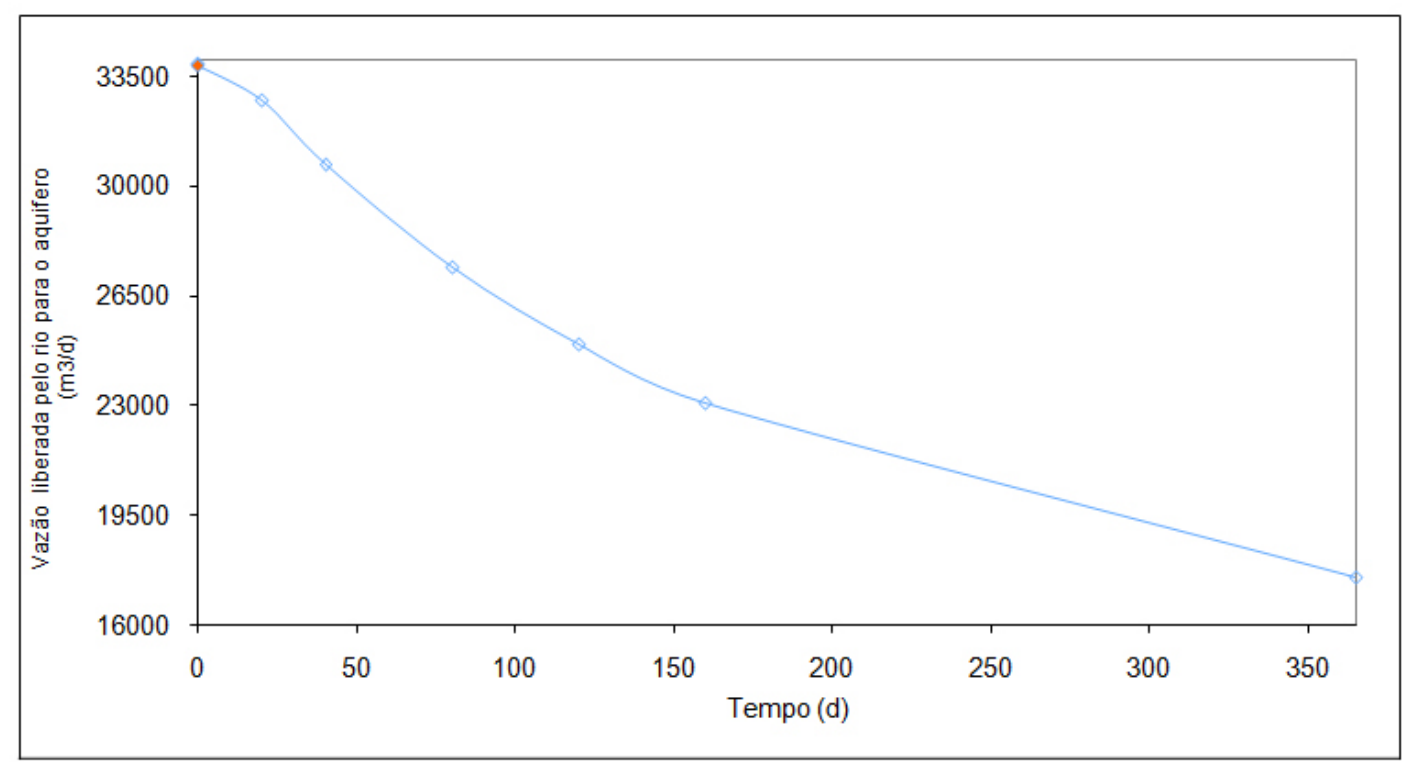

Figura 12: Vazão liberada pelo rio (calculada pelo MODFLOW). No tempo aproximadamente zero a vazão é a maior, porque neste tempo o gradiente hidráulico corresponde à diferença de cargas entre o rio perenizado e a superfície piezométrica máxima atual

Figure 12: Released by river flow (calculated by MODFLOW). At time zero the flow is about the most, because this time the hydraulic gradient is the difference in charges between the perennialized river and surface actual maximum.

\section{Renovação das reservas}

No equilíbrio, as reservas em águas subterrâneas se renovam mediante o aporte de águas de alimentação direta ou indireta que compensam as perdas do sistema. Neste caso, o volume de águas de renovação é igual à reserva reguladora ou, ainda, igual à infiltração eficaz. A taxa de renovação é a relação entre as reservas reguladoras $\left(R_{r}\right)$ médias e as reservas totais $\left(R_{t}\right)$, que corresponde à soma das reservas permanente $\mathrm{e}$ reguladora. Assim, de acordo com os itens acima, cerca de $9 \%$ das reservas do aquífero aluvial é anualmente renovado. O período de renovação é o tempo que seria necessário para reconstituir a reserva total se ela fosse totalmente esgotada. Em um aquífero em equilíbrio é a relação entre a reserva total $\left(R_{t}\right)$ e o volume anual de infiltração eficaz (ou volume anual de escoamento subterrâneo). O período encontrado para o aquífero aluvial da ilha de Limoeiro foi de 11 anos.

\section{Efeito da perenização do rio Jaguaribe}

A barragem do açude Orós foi concluída em 1961. Entre suas finalidades está a perenização do rio Jaguaribe, o curso d'água mais importante da região.

Com as cargas do rio antes da perenização e cargas médias com perenização, efetuouse simulações do fluxo subterrâneo na ilha de Limoeiro do Norte, sem recarga e com recarga, usando o modelo MODFLOW, observando a variação das cargas com o tempo. A malha usada e outras informações sobre a modelagem são dadas na metodologia.

Na primeira simulação, a condição de contorno foi a carga mínima do rio (Tabela 4), ou seja, cargas antes da perenização. As equipotenciais geradas, no estado estacionário, estão na Figura 13 , que correspondem à superfície piezométrica do aquífero aluvial. Na segunda simulação, no estado transiente, as cargas iniciais foram as geradas na 
primeira simulação, e a condição de contorno foi a carga média de perenização do rio (Tabela 5). Foi observado que as cargas do aquífero entram em equilíbrio (Figura 14) no tempo aproximado de 6.000 dias ( $\approx 17$ anos). Como o rio está perenizado há 40 anos, então, o sistema atualmente já estaria em equilíbrio, as retiradas do aquífero são compensadas pela recarga.

$\mathrm{Na}$ simulação sem recarga, as cargas calculadas (Figura 14) estão muito próximas das cargas observadas atualmente, o que indica que as retiradas (bombeamento) do aquífero aluvial, na ilha, são elevadas, superiores à recarga.

$\mathrm{Na}$ simulação com recarga, considerando $15 \%$ da precipitação, foi observado que as cargas também estabilizam com aproximadamente 6000 dias e com valores bem mais elevados (Figuras 15 e 16). Com a recarga, surge um divisor de águas no centro da ilha, o que não é verificado na superfície piezométrica atual. Atualmente, as cargas na ilha são menores que as cargas do rio, e os valores de $\delta^{18} \mathrm{O}$ na ilha indicam águas misturadas do rio e de chuva, não apenas de chuva (GOMES, 2005).

Há 18 anos foi construído o poço P05 e, de acordo com informações do proprietário, o nível estático era $4 \mathrm{~m}$; hoje o nível estático varia entre 7,7 e 9,8m. Naquela época ainda não havia um intenso cultivo de arroz (atualmente são plantados 500 ha em Limoeiro). Para um nível estático de 4m, a carga neste ponto (P05) está quase em equilíbrio com o rio. Provavelmente este era o cenário para a ilha antes das plantações, principalmente de arroz, que necessita, em média, $16,7 \times 10^{3} \mathrm{~m}^{3} / \mathrm{ha} /$ ciclo.

Tabela 4: Cotas antes da perenização do rio

Table 4: Altitudes before perennization of the river

\begin{tabular}{|c|c|c|c|c|c|}
\hline $\begin{array}{c}\text { Cota em relação à soleira do rio, } \\
\text { na Estação Peixe Gordo } \\
\text { (cm) }\end{array}$ & \multicolumn{5}{|c|}{ Cota em relação ao nível do mar } \\
$(\mathbf{m})$
\end{tabular}

Tabela 5: Cotas médias de perenização do rio

Table 5: Average altitudes after perennization of the river

\begin{tabular}{|c|c|c|c|c|c|}
\hline $\begin{array}{c}\text { Cota em relação a soleira do rio, na } \\
\text { Estação Peixe Gordo (1973-2003) } \\
(\mathbf{c m})\end{array}$ & \multicolumn{5}{|c|}{ Cota em relação ao nível do mar } \\
$(\mathbf{m})$
\end{tabular}




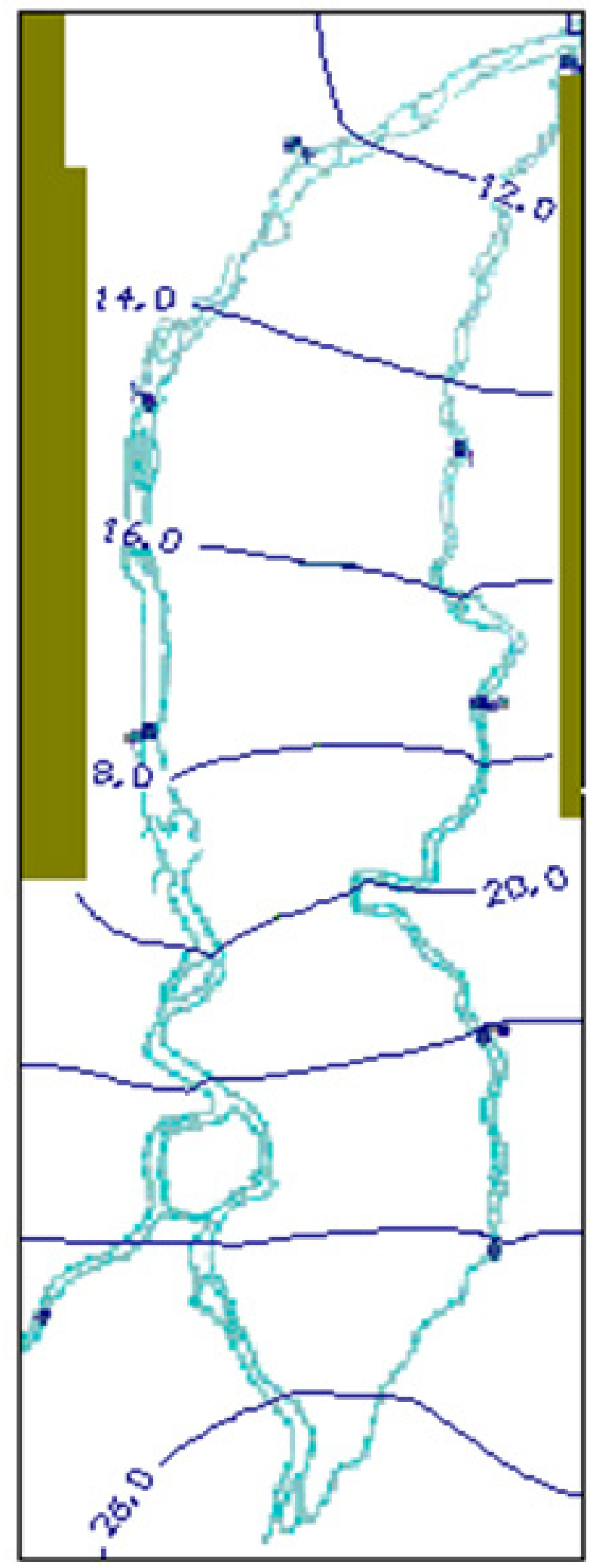

Figura 13: Equipotenciais para ilha de Limoeiro, com cotas constantes do rio como condição de contorno; antes da perenização - simulação no estado estacionário, sem recarga

Figure 13: Equipotentials on the isle of Limoeiro, with constant altitude in the river as boundary condition; before perennization - steady state simulation, without recharge 


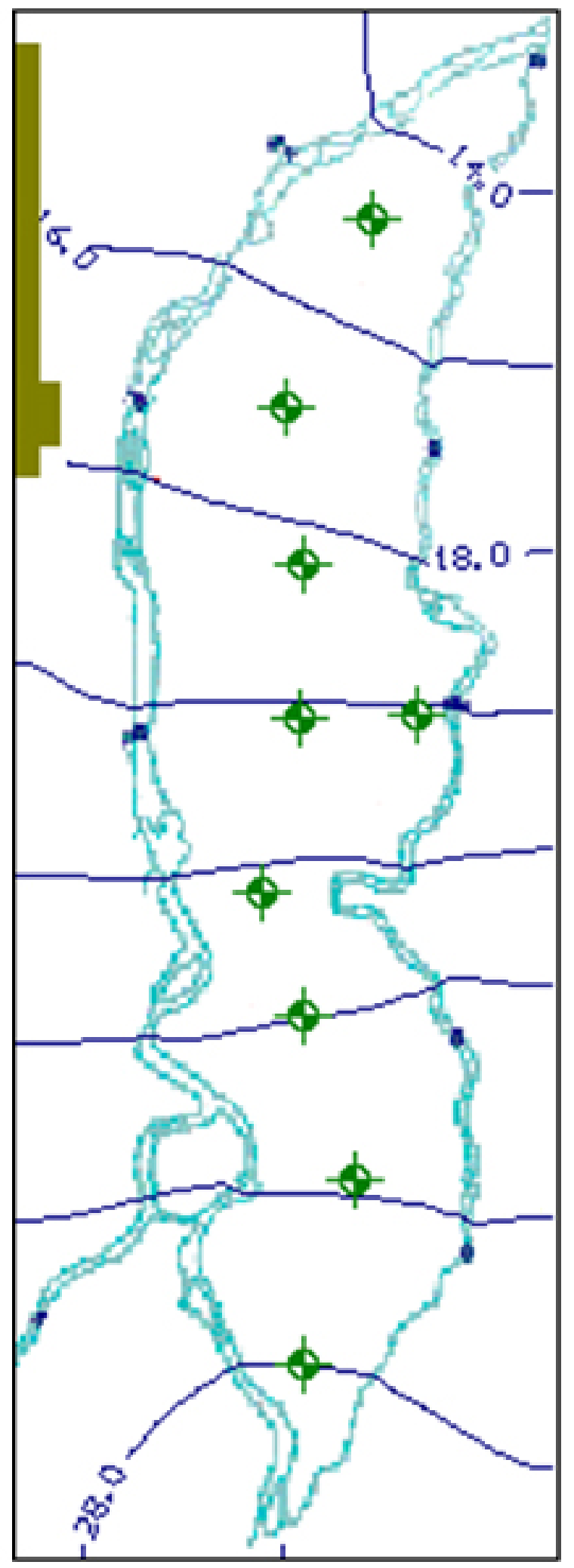

Figura 14: Equipotenciais no equilibrio ( $T \approx 17$ anos), com cotas constantes como condição de contorno; após a perenização - simulação no estado transiente, sem recarga ( $\$$ Poço de observação)

Figure 14: Equipotentials at equilibrium $(T \approx 17$ years), with constant altitude in the river as boundary condition; after perennization - transient state simulation, without recharge (-observation well) 


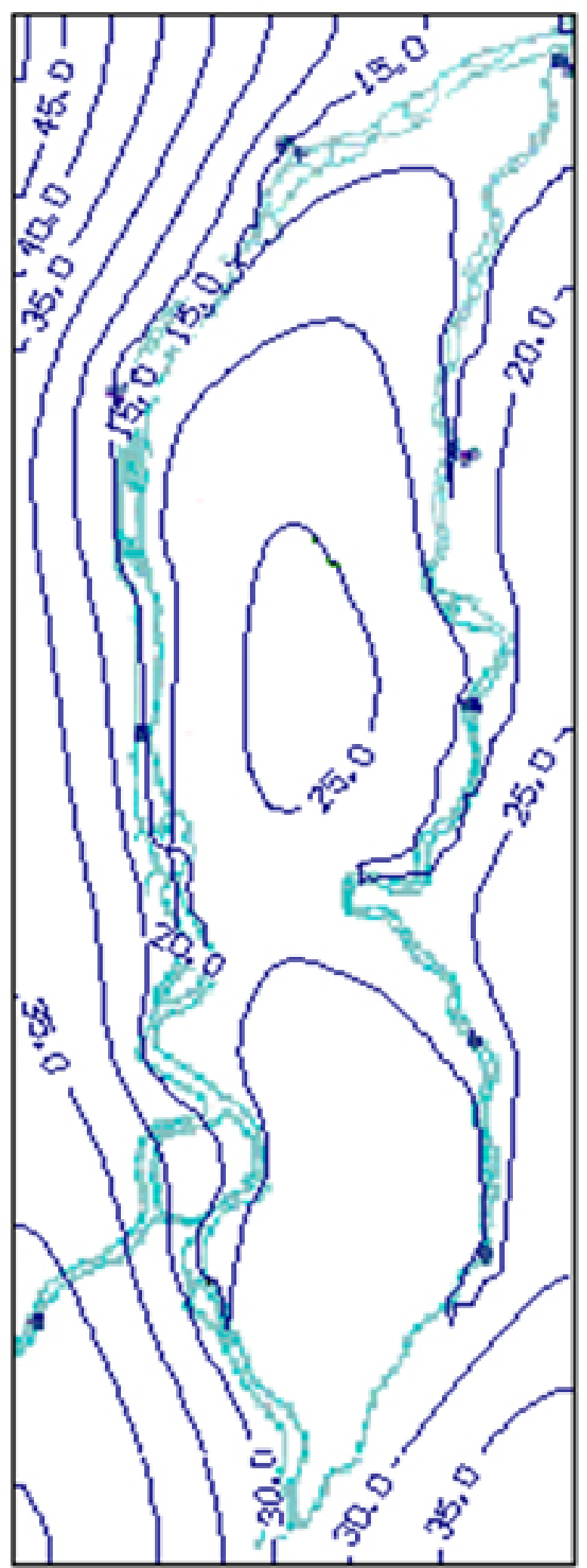

Figura 15: Equipotenciais para ilha de Limoeiro, com cotas constantes do rio como condição de contorno; antes da perenização - simulação no estado estacionário, com recarga

Figure 15: Equipotentials on the isle of Limoeiro, with constant altitude in the river as boundary condition, before perennization - steady state simulation, with recharge 


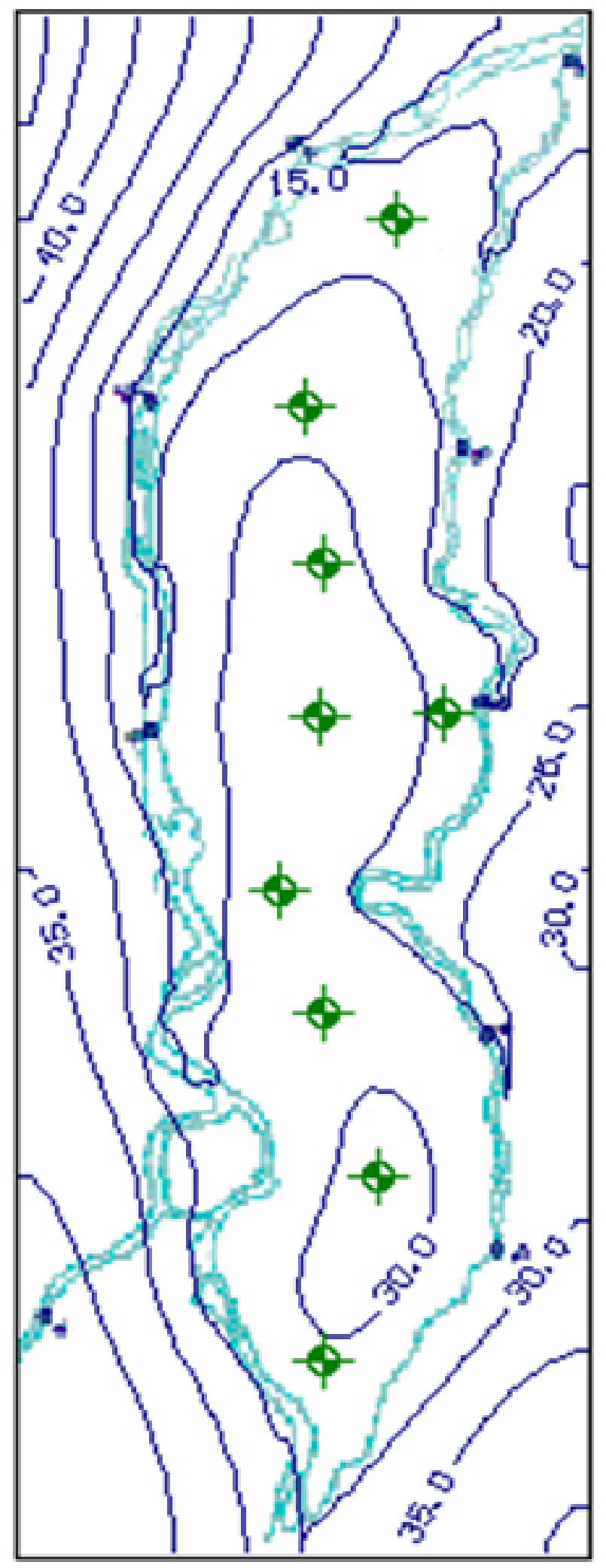

Figura 16: Equipotenciais no equilibrio ( $T \approx 17$ anos), com cotas constantes como condição de contorno; após a perenização - simulação no estado transiente, com recarga ( $\$$ Poço de observação)

Figure 16: Equipotentials at equilibrium $(T \approx 17$ years), with constant altitude in the river as boundary condition, after the perennization - transient state simulation, with recharge (-observation well) 


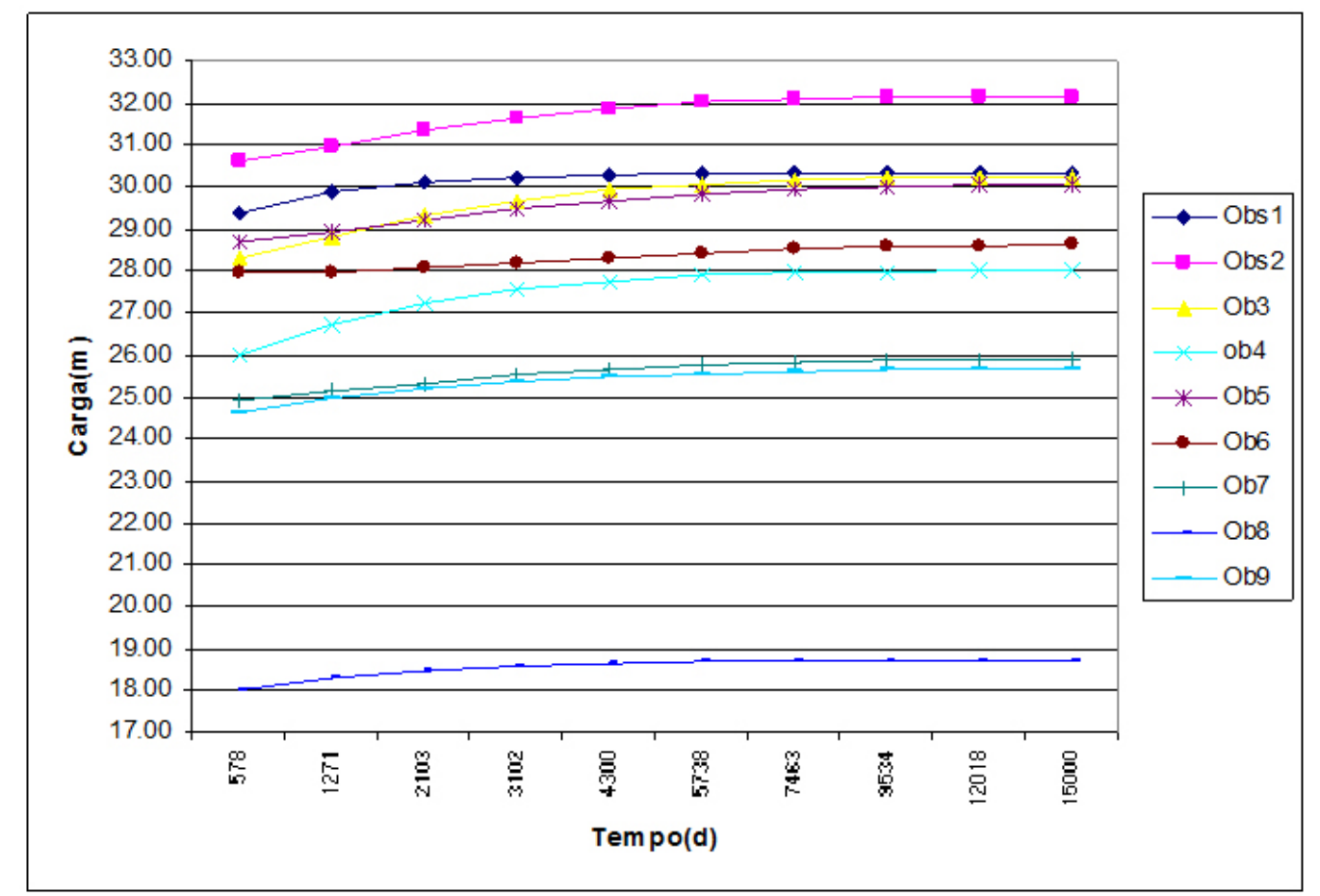

Figura 17: Cargas geradas pelo MODFLOW; a partir de aproximadamente 6000 dias o sistema entra em equilíbrio.

Figure 17: Heads generated by MODFLOW. At about 6000 days the system reaches equilibrium

\section{CONCLUSÃO}

O nível estático médio do aquífero aluvial é 6,7 $\mathrm{m}$, com variação anual da superfície hidrostática entre 0,4 a $2 \mathrm{~m}$. A superfície piezométrica do aquífero aluvial na ilha de Limoeiro apresenta gradiente médio fraco, de $0,5 \%$; porém, localmente, nas margens das zonas de depressão, aumenta para 2\%. Entre os dois rios (Jaguaribe Oeste e Quixeré) são observadas depressões na superfície piezométrica, sugerindo forte explotação de água e drenagem subterrânea das águas dos rios. A perenização do rio Jaguaribe teria feito o sistema rio-aquífero entrar em equilíbrio no tempo aproximado de 17 anos, com as cargas no aquífero superiores às atuais, formando um divisor de água na ilha de Limoeiro; no entanto, atualmente é observado rebaixamento da superfície piezométrica do aquífero. Torna-se necessário continuar com o monitoramento do nível das águas, superficiais e subterrâneas, como forma de preservação e controle do uso da água.

\section{Agradecimentos}

Á Fundação Cearense de Apoio ao Desenvolvimento Científico e Tecnológico (FUNCAP) e aos Laboratórios LGMA e LHG do Departamento de Geologia da UFC.

\section{REFERÊNCIAS BIBLIOGRÁFICAS}

ANA. Agência Nacional de Águas. Centro de documentação. Agropolo Baixo Jaguaribe: Informações básicas sobre o Plano Águas do Vale. COGERH/SEAGRI. 2002. Disponível em: <http://www.ana.gov.br/ AcoesAdministrativas/CDOC/ biblioteca
CatalogoPublicacoes.asp > Acesso: $10 \mathrm{dez}$ 2003

CABRAL, J. Movimento das Águas Subterrâneas. In: F.A.C. FEITOSA \& J.M. FILHO (eds.) Hidrogeologia: conceitos e aplicação. CPRM. LABHID-UFPE. Fortaleza. 
1997. p.35-52.

CAGECE. Companhia de Água e Esgoto do Ceará. Captação de Quixeré. Ampliação da captação. Relatório final. Fortaleza. 1982. 120p.

CAGECE. Companhia de Água e Esgoto do Ceará. Fichas de testes de bombeamento, no município de Russas. Captação de Russas. Programa de Emergência. 1999. 45p.

CASTANY, G. Prospección y explotación de las aguas subterráneas. Barcelona. Omega. 1975.

CPRM. Atlas de geologia e recursos minerais do Ceará: sistema de informações geográficasSIGE. Mapas na escala 1:500.000. CPRM Serviço Geológico do Brasil, 2003, 1CD-Rom CUSTÓDIO, E.; LLAMAS, M. R. Hidrologia subterrânea. Ediciones Omega. Barcelona. 2 ed. 1983. 1157p.

FETTER, C. W. Contaminant hydrogeology. Maxwell Macmillan International. 458p.

FREEZE, R. A.; CHERRY, J.A. Groundwater. New Jersey. Prentice Hall. 1979. 604p

GASPARY, J.; ANJOS, F. R. A; REBOUÇAS, A C.; MANUEL FILHO, J,; LEAL, O.;
GARAU, J.P. ; GUILLOT, P. Estudo geral das águas subterrâneas do Baixo Jaguaribe. In: Estudo Geral de Base do vale do Jaguaribe. Hidrogeologia. SUDENE/ASMIC. Recife. 1967. p.170-202.

GOMES, D.F. Estudo hidroquímico, isotópico e da dinâmica do nível estático das águas subterrâneas e superficiais da região de Limoeiro do Norte - Baixo Jaguaribe/Ceará. Tese de doutorado. Centro de Tecnologia. Universidade Federal do Ceará. 2005. 218p IBGE. Diagnóstico ambiental da bacia do rio Jaguaribe - Ministério do Planejamento e Orçamento - Fundação Instituto Brasileiro de Geografia e Estatística (IBGE) - Salvador. 1999.

IPLANCE. Fundação Instituto de Planejamento do Ceará. Atlas do Ceará. Fortaleza. 1997. 65p.

SALES NETO, P. Interação entre as águas do rio Jaguaribe e as do armazenamento subterrâneo no Baixo Jaguaribe - Ceará. Dissertação de mestrado. Departamento de Geologia. Universidade Federal do Ceará. Fortaleza. 1997. 63p. 
